Chapman University

Chapman University Digital Commons

ESI Working Papers

Economic Science Institute

4-2019

\title{
Reconsidering Rational Expectations and the Aggregation of Diverse Information in Laboratory Security Markets
}

Brice Corgnet

Emlyon Business School

Cary Deck

Chapman University, deck@chapman.edu

Mark DeSantis

ChapmanUniversity, desantis@chapman.edu

Kyle Hampton

Chapman University

Erik O. Kimbrough

Chapman University, ekimbrou@chapman.edu

Follow this and additional works at: https://digitalcommons.chapman.edu/esi_working_papers

Part of the Econometrics Commons, Economic Theory Commons, and the Other Economics Commons

\section{Recommended Citation}

Corgnet, B., Deck, C., DeSantis, M., Hampton, K., Kimbrough, E.O. (2019). Reconsidering rational expectations and the aggregation of diverse information in laboratory security markets. ESI Working Paper 19-11. Retrieved from

https://digitalcommons.chapman.edu/esi_working_papers/269/

This Article is brought to you for free and open access by the Economic Science Institute at Chapman University Digital Commons. It has been accepted for inclusion in ESI Working Papers by an authorized administrator of Chapman University Digital Commons. For more information, please contact laughtin@chapman.edu. 


\title{
Reconsidering Rational Expectations and the Aggregation of Diverse Information in Laboratory Security Markets
}

\author{
Comments \\ Working Paper 19-11
}




\title{
Reconsidering Rational Expectations and the Aggregation of Diverse Information in Laboratory Security Markets
}

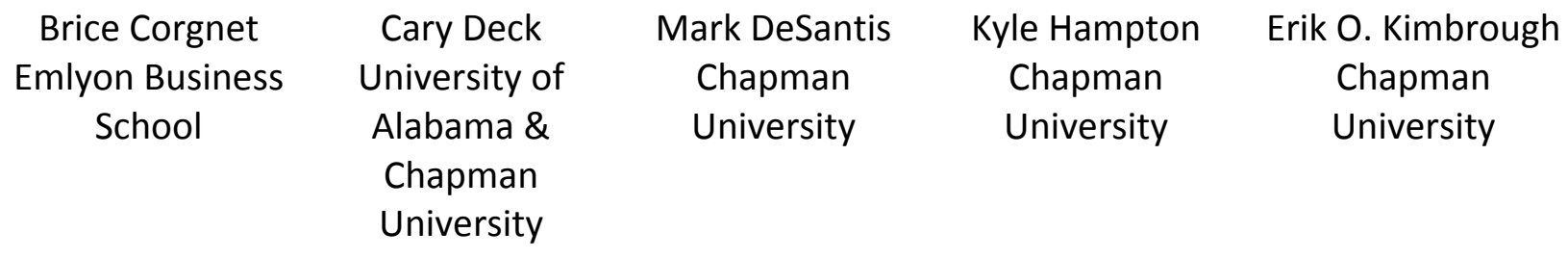

April 2019

\begin{abstract}
The ability of markets to aggregate diverse information is a cornerstone of economics and finance, and empirical evidence for such aggregation has been demonstrated in previous laboratory experiments. Most notably Plott and Sunder (1988) find clear support for the rational expectations hypothesis in their Series B and C markets. However, recent studies have called into question the robustness of these findings. In this paper, we report the result of a direct replication of the key information aggregation results presented in Plott and Sunder. We do not find the same strong evidence in support of rational expectations that Plott and Sunder report suggesting information aggregation is a fragile property of markets.
\end{abstract}

Keywords: Aggregation, Efficient Markets, Rational Expectations, Experiments, Replication

Acknowledgements: Brice Corgnet performed this research within the framework of the LABEX CORTEX (ANR-11-LABX-0042) of Université de Lyon, within the program Investissements d'Avenir (ANR-11-IDEX-007) operated by the French National Research Agency (ANR). The research was conducted with the approval of Chapman University's Institutional Review Board, application \#IRB-19-29. 


\section{Introduction}

The ability of markets to aggregate dispersed information has long played a critical role in the debate over the optimal allocation of scarce resources in Economics. Hayek (1945) was the first to emphasize the capacity of markets as a mechanism to aggregate and convey highly-dispersed information to the rest of society via prices. Although most economists are sympathetic to the Hayekian argument, the ongoing debate between classical and behavioral finance testifies to the existence of open disagreements regarding the extent to which the efficient markets hypothesis holds in practice, i.e., the extent to which market prices tend to accurately reflect available information (Fama, 1970; Fama, 2008; Shleifer, 2000; Thaler, 2005, 2015; Shiller, 2015). This debate is fueled by a lack of a widely-accepted methodology to gauge whether naturally occurring markets are indeed efficient. Fama (1991) argues that "market efficiency per se is not testable" (p. 1575). In the field, this is the case because private information is largely unobserved and because not all finance scholars agree on which asset pricing model should be used to assess whether a given piece of information is reflected in prices. These considerations would seem to imply that the efficient markets hypothesis (Fama, 1970) is not falsifiable.

However, the emergence of experimental markets (Chamberlain, 1948; Smith, 1962) made it possible for economists to construct markets in which they would not only have perfect control over the distribution of private information but also know the fundamental value of any asset (e.g. Bossaerts, 2009; Frydman et al. 2014; Noussair and Tucker, 2013). Experimental markets could thus allow researchers to study the aggregation of private information, rendering the efficient markets hypothesis falsifiable. This methodological breakthrough was initiated by Plott and Sunder (1988), hereafter P\&S, who designed experimental markets to gauge the extent to which dispersed private information was incorporated into prices. In their design, subjects traded assets that delivered one of three possible dividends at the end of each market period based on a randomly determined state $(X, Y$, or $Z)$. Each trader was endowed with private information ruling out one of the possible states (e.g. Not X). Because P\&S made sure half the traders were given one piece of information, while the other half were told the complementary piece of information (e.g. half told not $X$ and half told Not $Y$ ), the aggregate information held by market participants was complete (e.g. the state must be Z). They reported strong evidence that, in line with the efficient markets hypothesis, market prices can reflect the true asset value if there are contingent markets for each possible state (referred to in P\&S as Series B) or if there is a single asset yielding common state-specific dividends to all traders (referred to in P\&S as Series C). An equally important, but oft-ignored finding of $P \& S$, is the fragility of successful information aggregation. P\&S (p. 1117) highlight this in their conclusion when they point out that "not all markets can be depended upon to behave in accord with the rational expectations model." In particular, P\&S found that markets with a single asset but diverse state-specific 
dividends (referred to in $P \& S$ as Series $A$ ) do not yield prices consistent with the rational expectations model. ${ }^{1}$

The positive results of P\&S have been highly influential, serving as the basis for a wide variety of extensions and applications, which were followed by a wave of field studies discussing the successful use of prediction markets at major companies such as Hewlett-Packard, Intel, Google, Microsoft, Yahoo and IBM (Chen and Plott, 2002; Cowgill, Wolfers and Zitzewitz 2009; Gillen, Plott and Shum, 2017; see Deck and Porter 2013 for a survey). Prediction markets have come to be viewed as a mainstream tool for decision makers wanting to aggregate information (See Arrow et al. 2008).

Despite these encouraging results, evidence from a number of recent experimental studies has cast doubt on the robustness of the market's ability to aggregate dispersed private information even in the cases where P\&S found success. Several works using variants of the P\&S design with a single asset (Series $C$ ) have reported substantial mispricing (see Biais, Hilton, Mazurier and Pouget, 2005; Hanson, Oprea and Porter 2006; Veiga and Vorsatz 2010; Corgnet, DeSantis and Porter, 2015; 2019). Similarly, Page and Siemroth (2018) report a failure to aggregate private information in contingent claims markets, though their setup differed from P\&S (Series B), as they studied the more intricate case of aggregate uncertainty (see Anderson and Holt, 1997) in which all private signals available in the market cannot fully reveal the true value of the asset. ${ }^{2}$ Finally, mispricing has also been observed in setups which allow for costly acquisition of private information (e.g. Huber, Angerer and Kirchler, 2011; Page and Siemroth, 2017; Corgnet, Deck, DeSantis and Porter 2018).

Despite the seemingly contradictory evidence, no experimental work has attempted to directly replicate the findings of $P \& S$. Instead, previous works have modified the original P\&S design in potentially important ways, confounding direct comparisons to P\&S. For example, the works of Hanson, Oprea and Porter (2006), Veiga and Vorsatz (2010), Page and Siemroth (2018) and Corgnet, DeSantis and Porter $(2015 ; 2019)$ used computerized auctions instead of hand-run oral auctions. Although Biais, Hilton, Mazurier and Pouget (2005) use oral auctions, their procedures differ from $P \& S$ because their continuous double auctions were either preceded or followed by a call auction. In addition, no work in this literature has used the markets reported in P\&S (Series $B$ ) in which the value of dividends is heterogenous across traders.

Given the current state of the literature and practice, we believe it is crucial to revisit the question of information aggregation. To that end, we conducted a replication of the work of

\footnotetext{
${ }^{1}$ A follow-up study by Forsythe and Lundholm (1990) showed that full information aggregation could be achieved when the same cohort of subjects were re-invited for a second trading session where the distribution of heterogeneous dividend values of the single asset was common knowledge among all traders.

${ }^{2}$ Page and Siemroth (2018) consider a common dividend value environment.
} 
P\&S so as to gauge the robustness of their results as well as shed light on the factors that might promote or hinder the aggregation of diverse information.

\section{The Experiments of Plott and Sunder}

In P\&S traders are endowed with an amount of money, denoted in Francs, and assets called certificates that can be bought and sold by the traders using a continuous double auction. At the end of each trading period, certificates pay their owner a dividend that depends on the state of nature, which can be $X, Y$, or $Z$. The state of nature is not known by any trader, but the probability distribution over states is common information. Further, half the traders are informed of one unrealized state; while, the other half are informed of the other unrealized state. So for example, if the state is $X$, then half the traders are informed the state is not $Y$ and half are informed it is not $Z$. In aggregate the traders have sufficient information to determine that the state is $X$. If markets successfully aggregate dispersed information, then the price should reflect the value the traders have for the certificates in the realized state.

P\&S present the results of 11 total sessions from three series of markets. In Series A markets, different trader types had different dividend values for each state of nature, and there was a single asset trading in the market. In Series B markets, as in Series A, different types of traders had different dividend values, but there was a complete set of contingent claims, each of which only delivered a payout if the associated state was realized. ${ }^{3}$ Thus, the difference between Series A and Series B is the type of asset(s) - single or contingent claim - that was tradable. In Series $C$, dividend values were the same for all traders, and there was a single tradable asset. The difference between Series $A$ and Series $C$ is the diverse or common dividend value of the single asset. Series $A$ is arguably the most complex setup of the three; while, both Series $B$ and Series $C$ introduce simplifications. As a result, one can view Series $A$ as the experimental baseline and Series B and Series $C$ as treatments.

In P\&S, the information aggregation hypothesis was rejected whenever the data on prices, allocation and profits were not better explained by the Rational Expectations model (RE, hereafter) model compared to two alternative models: Prior Information and Maximin. We describe these models below.

\section{Rational expectations (RE)}

If the pooled information of all traders identifies the asset value with certainty, the fullyrevealing rational expectations equilibrium price is the true asset value. To illustrate the mechanics, consider the case in which it is common knowledge that the asset value is 50, 240, or 490 each with equal probability. Suppose the true value is 50 . In this case, half the traders

\footnotetext{
${ }^{3}$ Diverse dividend values ensure that there are always gains from trade.
} 
would be given the signal "Not 240 " and the other half would be given the signal "Not 490 ". Before any trading occurs, the traders who receive the "Not 240" signal value the asset at 270; whereas, the "Not 490 " traders value the asset at 145 . These traders would also recognize that should anyone have received a "Not 50" signal that trader would value the asset at 365 . The lack of traders willing to purchase the asset at a price between 270 and 365 thus reveals that none of the traders received the "Not 50 " signal. This reveals that the true value must be 50 , and so 50 would be the equilibrium price.

\section{Prior information (PI)}

In the prior information model, traders do not infer information regarding other traders' signals from market prices, but they do apply Bayes' rule to compute the expected asset value given the public information on the prior probability that a state is realized and their own private information (Lintner, 1969). Each individual trader is assumed to be willing to spend all her cash to buy assets at a price below her prior belief of its value and would sell all her certificates at any price above her prior belief. With sufficient liquidity, the market price will equal the prior belief of the trader type with the highest prior belief. Again using the example where 50, 240, and 490 are equally likely, a trader who was informed the value was not 50 would buy at prices below 365 and sell at prices higher than this. A trader who was informed the value was not 490 would buy at prices below 145 and sell at prices higher than this. Thus, the result when the true value is 240 would be a price of 365 .

\section{$\operatorname{Maximin}(M M)$}

Similar to $\mathrm{Pl}$, market prices do not reveal all available private information in this model. Instead, a trader is assumed to buy the asset only when she is certain that the price is equal to or below the minimum dividend it could possibly yield, given the public information and her private information. With sufficient liquidity, the market price predicted by this model is equal to the minimum belief of the trader type with the highest belief of the minimum possible valuation of the asset. Returning to the case in which the true value is equally likely to be 50,240 , or 490 , a trader who is informed the true value is not 50 would buy at any price below 240 while a trader who is informed the value is not 240 would only pay at most 50 . Thus, the price would be 240 when the true value was 490 .

In Series $A, P \& S$ rejected the hypothesis that market prices aggregated private information. However, $P \& S$ report successful information aggregation in Series $B$ and $C$ which is when the RE model outperforms the PI and MM models in predicting prices (see Table III in P\&S, p. 1105), certificate allocations (Table IV in P\&S, p. 1106) and profit distributions (Table V in P\&S, p. 1107). These significant results are captured in Conclusions 2,3 and 4 in P\&S. 
The authors note "The fact that both the second and third series perform as predicted by the RE model leads us to suspect that the existence of instruments which enable traders to link the actions of others to a source of motivation is important to the information aggregation function of markets" (P\&S, p. 1086). Thus, P\&S suggest that information aggregation is not a robust property of markets, but can occur under certain circumstances. In particular, they emphasize that the presence of a full set of contingent claims is crucial to transform an inefficient market (Series A) into an efficient one (Series B): "The introduction of a complete set of Arrow-Debreu securities transformed a market that was operating inefficiently into a market that rapidly achieved a rational expectations equilibrium." (P\&S, p. 1117).

\section{Replication Experiments}

Following the replication procedures used by Camerer et al. 2016 (p. 1433), we attempted to replicate the most important statistically significant finding of the original study. For P\&S that finding is that information aggregation successfully occurs in Series B and C markets. P\&S ( $p$. 1116) state "On the positive side, experiments in the contingent claims markets (Series B) and in the uniform dividends markets (Series C) demonstrate that markets can aggregate diverse information in a manner consistent with rational expectations models."

Our replication thus seeks to assess whether asset prices reveal all available private information in Series B and C markets. Following P\&S, we compare the predictive ability of the RE model to that of PI and MM. Our replication attempt was preregistered in the AEA RCT Registry as AEARCTR-0003660.

\section{Market Environment}

The parameters for the markets are shown in Table 1, which is a subset of Table I (P\&S, p. 1088). We replicated Markets 4, 5, 7, 8, and 9 which correspond to Series B and C. The only change from $P \& S$ is the exchange rate for converting lab earnings into cash payments. To account for the cost of living difference in the approximately thirty years that have transpired since the original data were collected, the dollar per franc exchange rates have been doubled. ${ }^{4}$ Within each series, all traders in a session started with the same endowment of cash and certificates at the beginning of each market period. As the initial endowment of Francs represents a loan from the experimenter, traders had to pay a fixed cost at the end of each market to repay this loan, meaning that subjects' earnings were driven solely by dividends and

\footnotetext{
${ }^{4}$ The cost of living has indeed doubled in the US between 1988 and 2018 given an average annual inflation rate of $2.5 \%$ over that period. Note that the original experiments and our replication use an experimental currency called francs that is converted into local currency at the end of the session. For most of P\&S and all of our markets, that currency is dollars. However, Markets 7 and 8 of P\&S were conducted in India and thus payments were converted into rupees.
} 
capital gains/losses. The predicted prices under $\mathrm{RE}, \mathrm{PI}$, and $\mathrm{MM}$ as well as the predicted ending allocation of certificates can be found in Table II (P\&S, pp. 1091-1092) and are reproduced in Appendix A for each series, trader type, and realized state of nature.

Table 1. Market Parameters

\begin{tabular}{|c|c|c|c|c|c|c|c|c|c|c|c|c|}
\hline \multirow{2}{*}{$\begin{array}{l}\text { Market } \\
\text { (Series) }\end{array}$} & \multirow{2}{*}{$\begin{array}{l}\text { Trader } \\
\text { Type }\end{array}$} & \multirow{2}{*}{$\begin{array}{l}\text { Number } \\
\text { of Traders }\end{array}$} & \multicolumn{2}{|c|}{ Initial Endowment } & \multirow{2}{*}{$\begin{array}{l}\text { Fixed } \\
\text { Cost }\end{array}$} & \multirow{2}{*}{$\begin{array}{c}\$ / \\
\text { Franc }^{B}\end{array}$} & \multicolumn{3}{|c|}{ Dividends } & \multicolumn{3}{|c|}{ Probabilities } \\
\hline & & & Certificates & Francs & & & $x$ & $Y$ & Z & $x$ & $Y$ & Z \\
\hline \multirow{3}{*}{4 (B) } & I & 4 & 2 & 10,000 & 10,000 & 0.006 & 70 & 130 & 300 & \multirow{3}{*}{0.35} & \multirow{3}{*}{0.20} & \multirow{3}{*}{0.45} \\
\hline & II & 4 & 2 & 10,000 & 10,000 & 0.006 & 230 & 90 & 60 & & & \\
\hline & III & 4 & 2 & 10,000 & 10,000 & 0.006 & 100 & 160 & 200 & & & \\
\hline \multirow{3}{*}{$5(B)$} & I & 4 & 2 & 15,000 & 15,000 & 0.005 & 140 & 260 & 600 & \multirow{3}{*}{$1 / 3$} & \multirow{3}{*}{$1 / 3$} & \multirow{3}{*}{$1 / 3$} \\
\hline & II & 4 & 2 & 15,000 & 15,000 & 0.005 & 460 & 180 & 120 & & & \\
\hline & III & 4 & 2 & 15,000 & 15,000 & 0.005 & 200 & 320 & 400 & & & \\
\hline 7 (C) & I & 12 & 4 & 25,000 & 25,000 & 0.003 & 50 & 240 & 490 & $1 / 3$ & $1 / 3$ & $1 / 3$ \\
\hline 8 (C) & 1 & 12 & 2 & 25,000 & 25,000 & 0.003 & 125 & 375 & 525 & $1 / 3$ & $1 / 3$ & $1 / 3$ \\
\hline $9(C)$ & 1 & 12 & 4 & 25,000 & 25,000 & 0.003 & 50 & 240 & 490 & 0.35 & 0.45 & 0.20 \\
\hline
\end{tabular}

\section{Power and Sample Size}

Following Camerer et al. (2016), our aim was to ensure a statistical power of at least $90 \%$ to detect the P\&S findings at a 5\% significance level; thus, we adopt their method and estimate the multiple of the original sample size that would be needed to achieve $90 \%$ power by using the standard $z$-test power formula $\left(\frac{3.242}{z}\right)^{2}$ where $z$ is the standard normal test statistic associated with the $p$-value of the original study. The main statistically significant results of P\&S correspond to the comparison between the RE model and the other two models regarding prices (P\&S, Table III) allocations (P\&S, Table IV) and profits (P\&S, Table V). Regarding the result on prices and profits, the required sample size is 3.019 times as large as the original sample, as the reported p-values are all equal to 0.031 , which is associated with a $z$ statistic of 1.866 . Regarding allocations, the $p$-value is 0.048 so that the multiple of the original sample size that would be needed is equal to 3.791. We thus opted for a multiple of 4 and collected four times as much data as the original study in order to have sufficient statistical power. This value falls within the normal range of multiples used in recent replication attempts in economics and social sciences (see Camerer et al. 2016; 2018). We thus recruited a total of 144 subjects. ${ }^{5}$ All participants were recruited from Chapman University's Economic Science Institute subject pool

\footnotetext{
${ }^{5}$ The number of subjects is less than 4 replicates $\times 5$ markets $\times 12$ traders because Markets 5 and 8 involved experienced traders as discussed in the next subsection.
} 
and were undergraduate students at that institution with no prior experience in information aggregation markets.

\section{Subject Experience and Earnings}

Because the duration and required experience varied across the markets in P\&S, subjects were recruited for different durations with different participation payments and average earnings. ${ }^{6}$ We were also careful to match the experience levels in P\&S (see Table I, p. 1088). In Market 8, the subjects were experienced in Market 7. In P\&S this means that the subjects were participating with the exact same group of people in the two markets, since there were 12 people in each market, and there was only one replicate of each market. However, in P\&S the subjects in Market 5 were experienced either in Market 3 or 4 . Thus, our Market 5 sessions were formed by combining half the subjects in one Market 4 session with half the subjects in another Market 4 session. The two remaining halves were also combined into a separate Market 5 session. Table 2 summarizes the details of our experimental sessions.

Table 2. Summary of Experimental Sessions

\begin{tabular}{|c|c|c|c|c|c|c|c|}
\hline $\begin{array}{l}\text { P\&S Market } \\
\text { and Series }\end{array}$ & Experience & $\begin{array}{c}\text { Subjects / } \\
\text { Session }\end{array}$ & Periods $^{A}$ & Sessions & $\begin{array}{c}\text { Participation } \\
\text { Payment }^{B}\end{array}$ & Duration $^{C}$ & $\begin{array}{c}\text { Average } \\
\text { Earnings } \\
\text { (USD) }^{\mathrm{D}}\end{array}$ \\
\hline $4 \mathrm{~B}$ & None & 12 & 13 & 4 & $\$ 7$ & $210 \mathrm{~min}$ & 27.19 \\
\hline $5 B$ & Market 4 & 12 & 9 & 4 & $\$ 30$ & $150 \mathrm{~min}$ & 33.89 \\
\hline $7 \mathrm{C}$ & None & 12 & 14 & 4 & $\$ 7$ & $180 \mathrm{~min}$ & 39.78 \\
\hline $8 C$ & Market 7 & 12 & 7 & 4 & $\$ 27$ & $120 \mathrm{~min}$ & 15.64 \\
\hline $9 \mathrm{C}$ & None & 12 & 17 & 4 & $\$ 15$ & $210 \mathrm{~min}$ & 53.68 \\
\hline
\end{tabular}

${ }^{A}$ In periods 10-13 of Market 4 and 10-16 of Market 5, traders also completed Series A markets in P\&S. We followed this procedure for Market 4, although we are not interested in analyzing Series A for which P\&S did not report successful information aggregation. Throughout the remainder of this paper, when we refer to Market 4 we mean the Series $B$ portion of the market in periods 1-9. We did not complete periods 10-16 (Series A markets) in Market 5 as, unlike Market 4 traders who are recruited to participate in Market 5 (see P\&S), this additional experience of Series A markets at the end of the experiment could not have impacted any behavior relevant to our replication endeavor.

${ }^{B}$ The participation payments for sessions of Markets 5 and 8 were large to ensure that subjects returned from Markets 4 and 7, respectively to ensure that we were able to match the experience levels of subjects in P\&S (see Table I of P\&S, p. 1088). Markets 7 and 8 were conducted on the same day, with a one-hour lunch break in between. Markets 4 and 5 were conducted either 1 or 2 days apart. For every Market 5 session, two subjects with experience in Market 9 were recruited as standbys in case a Market 4 subject did not return for Market 5 . In one Market 5 session a single standby was used as an alternate. To further encourage the subjects to return for the second session, Market 4(7) earnings were not paid until the end of Market $5(8)$, with subjects only receiving the participation payment at the end of Market 4(7).

${ }^{\mathrm{C}}$ The duration denotes the length of time for which the participants were recruited.

${ }^{D}$ The earnings exclude the participation payments.

\footnotetext{
${ }^{6}$ The lab's policy required that subjects be compensated in part based upon study duration.
} 


\section{Procedures}

Conduct of each session closely followed the procedures laid out in P\&S. P\&S (p. 1118) note that steps "were essentially similar to those described ... in Plott and Sunder (1982) with appropriate modifications to the instructions..." Thus, all handouts and instructions for this hand-run experiment, which are available in Appendix B, are based on details in Plott and Sunder (1982) and reflect differences that were noted in P\&S to the fullest degree possible.

Each session consisted of 5 stages after subjects provided informed consent and a general script was read aloud.

Stage 1. Subjects were trained with the mechanism (a bingo cage) used to draw the state of nature. In Plott and Sunder (1982, p. 693), it is noted that 10-20 draws were completed until most subjects predicted the most likely outcome. In our replication, there were always exactly 10 draws for this training.

Stage 2. Subjects were trained with the mechanism to provide signals (referred to as clues) about the state of nature. P\&S note (p. 1118) that this training lasted between 8 and 10 trials. In our replication, there were always exactly 10 draws for this training. Subjects were given a Clue Sheet with 30 rows. The first 10 rows were used for training, and then their clue for the first market period was on row 11. This ensured that the number of possible periods on their Profit Sheets matched the number of remaining rows in the Clue Sheet, post-training.

Stage 3. Subjects were given an explanation of the market rules. Because we wanted to use the same sequence of state realizations as in P\&S and did not want to deceive the subjects, rather than continuing to randomly draw the state with a bingo cage as in Stage 1, our subjects were informed that "The outcomes were determined before the experiment began by drawing a ball from a bingo cage in a manner similar to what was described earlier." The subjects were not informed that the draws occurred thirty years before the session. We also went through an example sequence of bids, asks, and acceptances. The example varied based on whether one or multiple assets were available for trade. As in P\&S, subjects could hold short positions during trading, but incurred a penalty equal to 300 francs plus the highest transaction price in that period per unit short at the end of a trading period. This contrasts with Plott and Sunder (1982, p. 696) where short positions were not allowed, and hence this necessitated a modification to the instructions (see Appendix B).

Stage 4. The market was conducted for several periods, referred to as years in the experiment. Each period lasted for 7 minutes, and all bids, asks, and contracts were left 
visible on the board until the period ended. We conducted the sessions in rooms with ample whiteboard space, and we never had to erase information mid-period. The Information and Record Sheets were collected at the end of each period, and new Information and Record Sheets were handed out before the start of each period subjects kept their Profit Sheet throughout Stage 4. In our replication, subjects were allowed to use basic four-function calculators to update their Information and Record Sheets and Profit Sheet. Bids, asks, and contracts from previous periods were erased before the next period began. Subjects did not know how many periods of trading there would be, as the Profit Sheet always listed 20 periods.

Stage 5. The subjects received their payment in private and were dismissed from the experiment.

In Market 4 where the series type changes mid-session, the subjects repeated Stage 3 after period 9. In Markets 5 and 8 , which involve only experienced subjects and were conducted as brand-new sessions, we repeated all five stages.

Finally, to guard against any bias from the auctioneer, the person serving in that role was unaware of the rational expectations price in every case and unfamiliar with the specifics of P\&S, although that person had experience conducting double auctions in a classroom setting.

\section{Results}

In this section we present our results in a manner parallel to the presentation in P\&S. We first show the graphs representing all asset prices in each period of the four replications of each market. Horizontal lines indicate the predictions of the three competing models. The width of each figure is standardized to facilitate period-by-period comparisons across markets because despite the common duration of each period, the number of periods varies substantially by market. ${ }^{7}$ A first visual inspection, as done in P\&S, suggests that prices differ from the RE model predictions regardless of the series and the market. In Table 3, we assess these differences using the same statistical approach as in P\&S.

Tables 3, 4, and 5 present the same analyses for the replication data that P\&S present in Tables III, IV, and V for the original data (P\&S, pp. 1105-1107). They are used to assess Conclusions 2, 3 , and 4 of $\mathrm{P} \& \mathrm{~S}$ that RE will outperform both $\mathrm{PI}$ and MM models in predicting prices (Table 3 ), allocations (Table 4) and profits (Table 5). We did not replicate these conclusions, as the RE model did not outperform both models at a $5 \%$ significance level, regardless of whether we look at prices, allocations or profits.

\footnotetext{
${ }^{7}$ The trades are presented in sequential order, but timing within the 7-minute trading period is not reflected.
} 
Figure 1a. Prices in Market 4 Sessions - Asset X

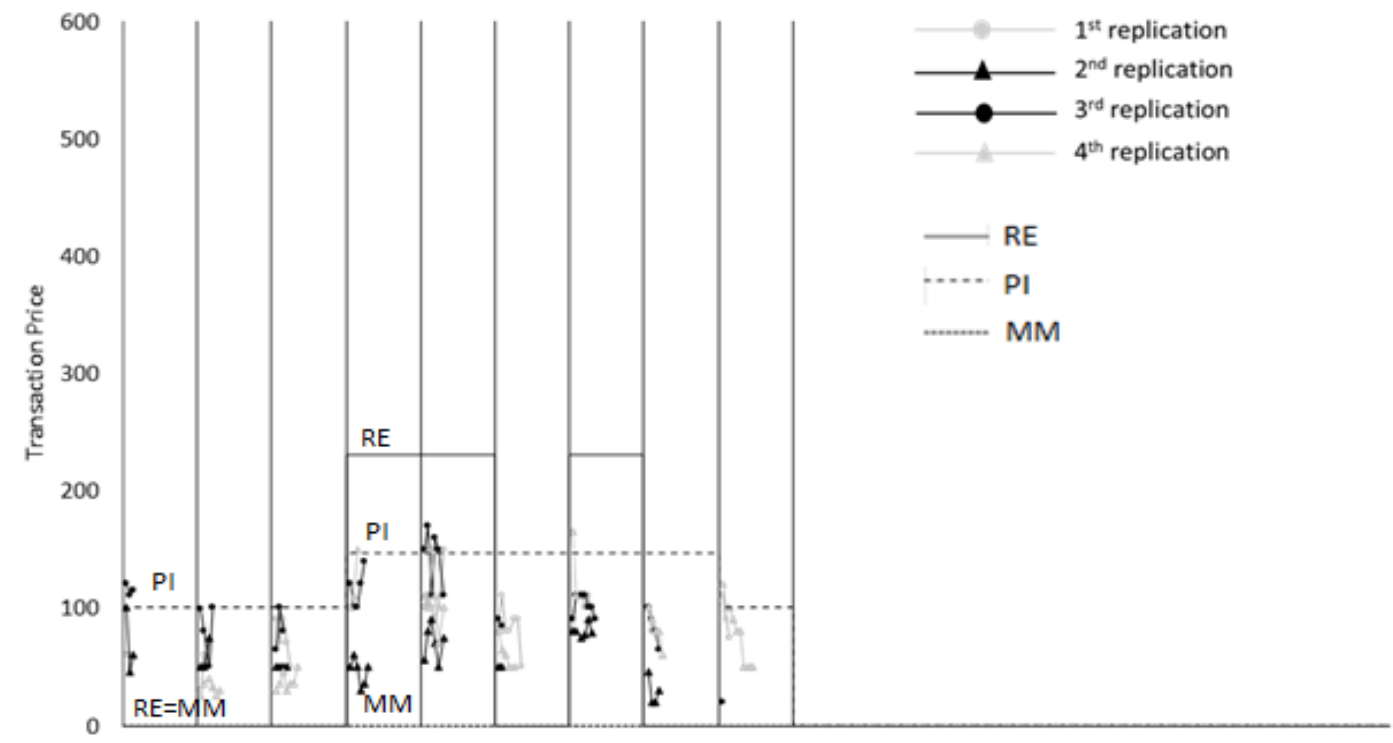

$\begin{array}{llllllllll}\text { Period } & 1 & 2 & 3 & 4 & 5 & 6 & 7 & 8 & 9\end{array}$

$\begin{array}{llllllllll}\text { State } & Z & Z & Z & X & X & Y & X & Y & Z\end{array}$

Average Prices

$\begin{array}{llllllllll}\text { P\&S } & 97 & 10 & 20 & 170 & 215 & 80 & 215 & - & -\end{array}$

$\begin{array}{llllllllll}\text { Rep } & 84 & 52 & 57 & 88 & 107 & 73 & 98 & 69 & 78\end{array}$

Figure 1b. Prices in Market 4 Sessions - Asset $Y$

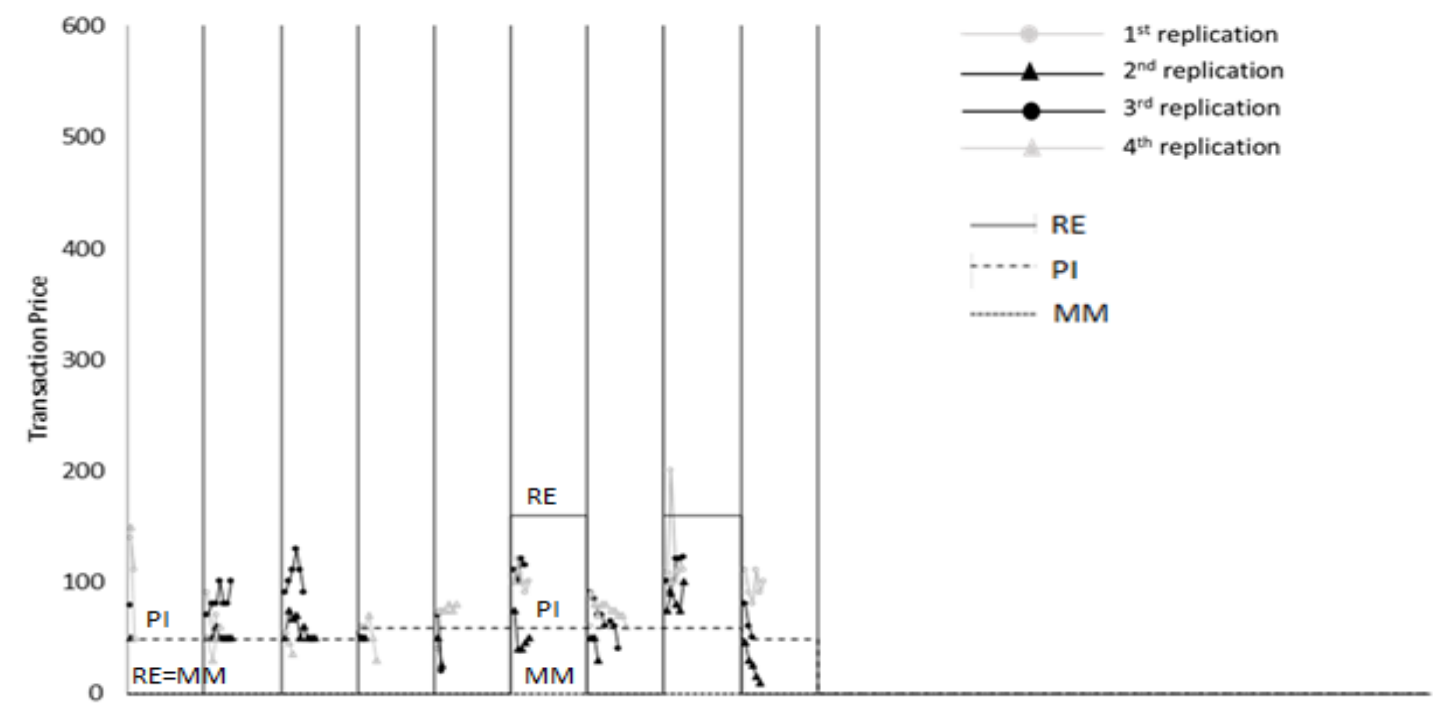

$\begin{array}{llllllllll}\text { Period } & 1 & 2 & 3 & 4 & 5 & 6 & 7 & 8 & 9\end{array}$

$\begin{array}{llllllllll}\text { State } & Z & Z & Z & X & X & Y & X & Y & Z\end{array}$

Average Prices

$\begin{array}{llllllllllll}\mathrm{P} \& \mathrm{~S} & 58 & 57 & - & 2 & - & 154 & 1 & 158 & -\end{array}$

$\begin{array}{llllllllll}\text { Rep } & 97 & 64 & 72 & 53 & 58 & 89 & 67 & 107 & 64\end{array}$ 
Figure 1c. Prices in Market 4 Sessions - Asset Z

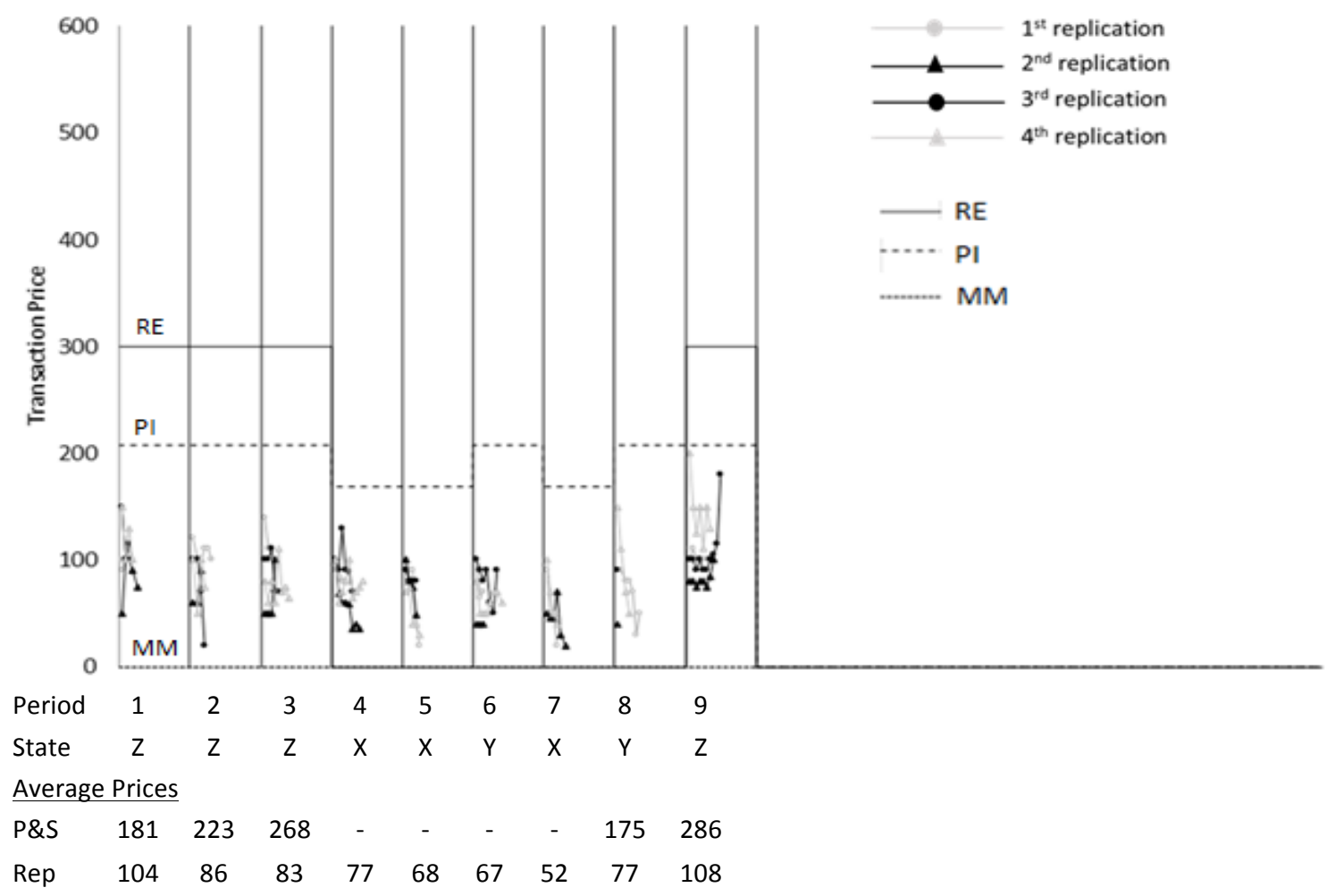

Figure 2a. Prices in Market 5 Sessions - Asset X

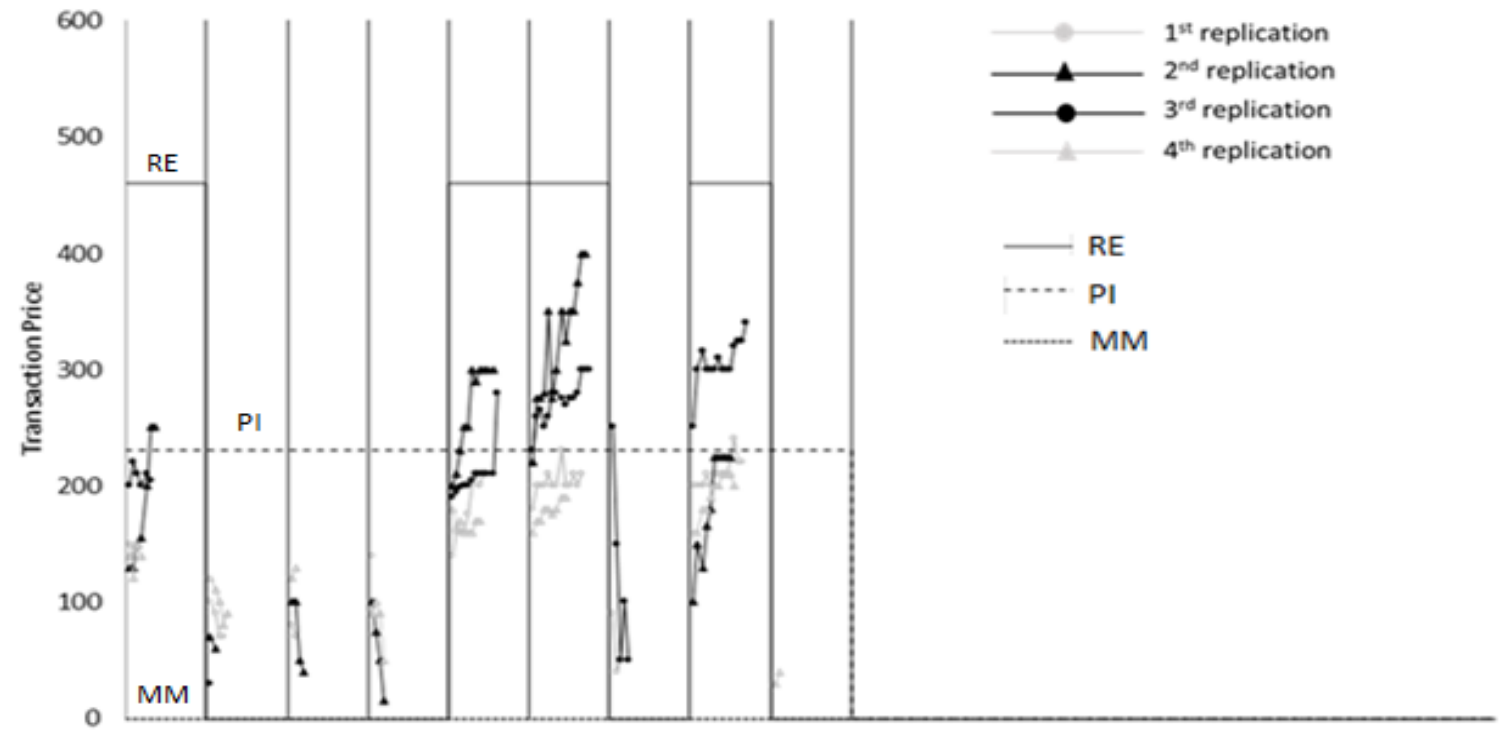

$\begin{array}{llllllllll}\text { Period } & 1 & 2 & 3 & 4 & 5 & 6 & 7 & 8 & 9 \\ & X & Z & Y & Y & X & X & Y & X & \end{array}$

Average Prices

$\begin{array}{llllllllll}P \& S & 181 & 100 & 46 & 4 & 250 & 385 & - & 414 & -\end{array}$

$\begin{array}{llllllllll}\text { Rep } & 175 & 83 & 86 & 79 & 210 & 252 & 98 & 229 & 35\end{array}$ 
Figure 2b. Prices in Market 5 Sessions - Asset $Y$

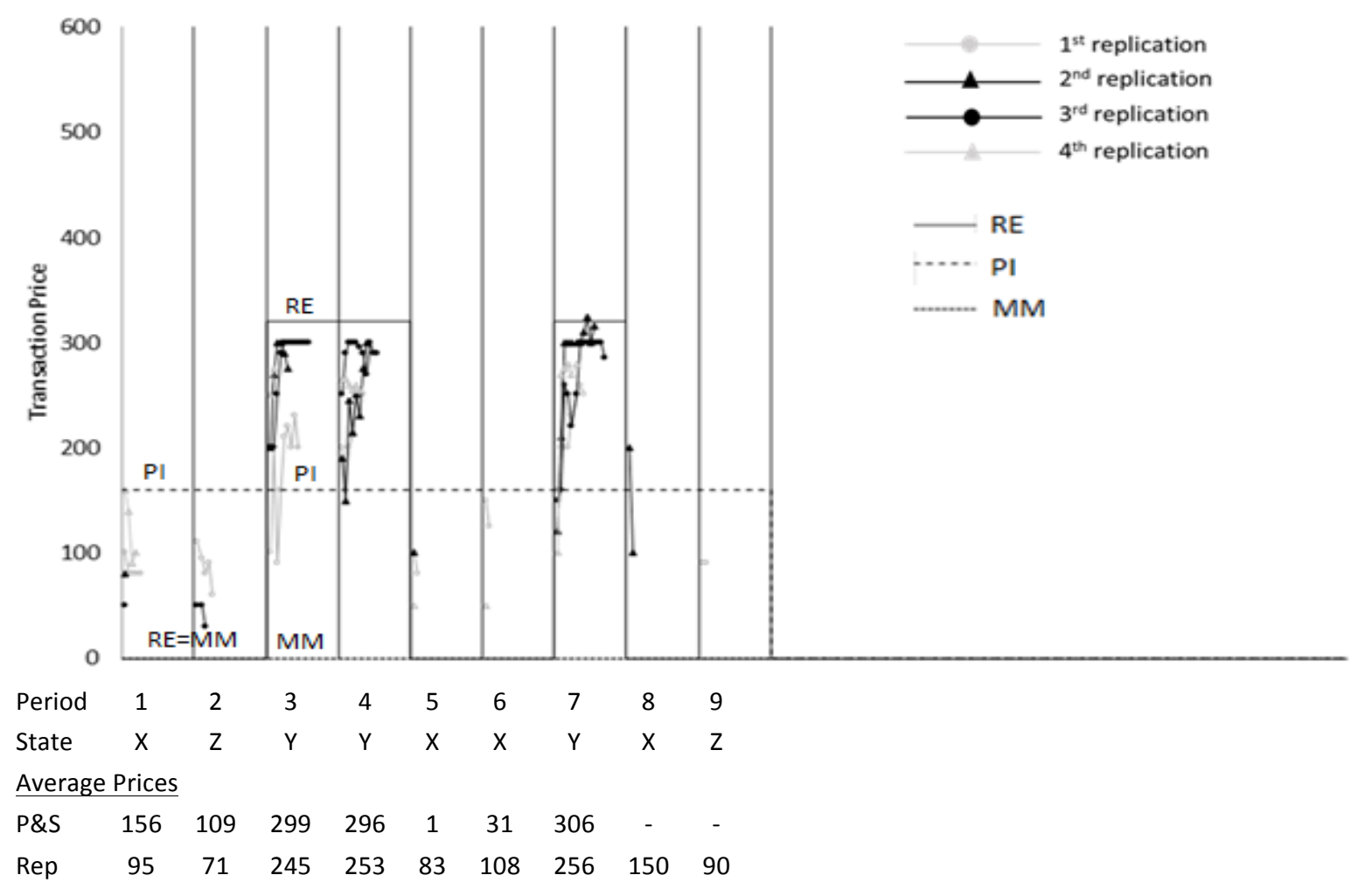

Figure 2c. Prices in Market 5 Sessions - Asset Z

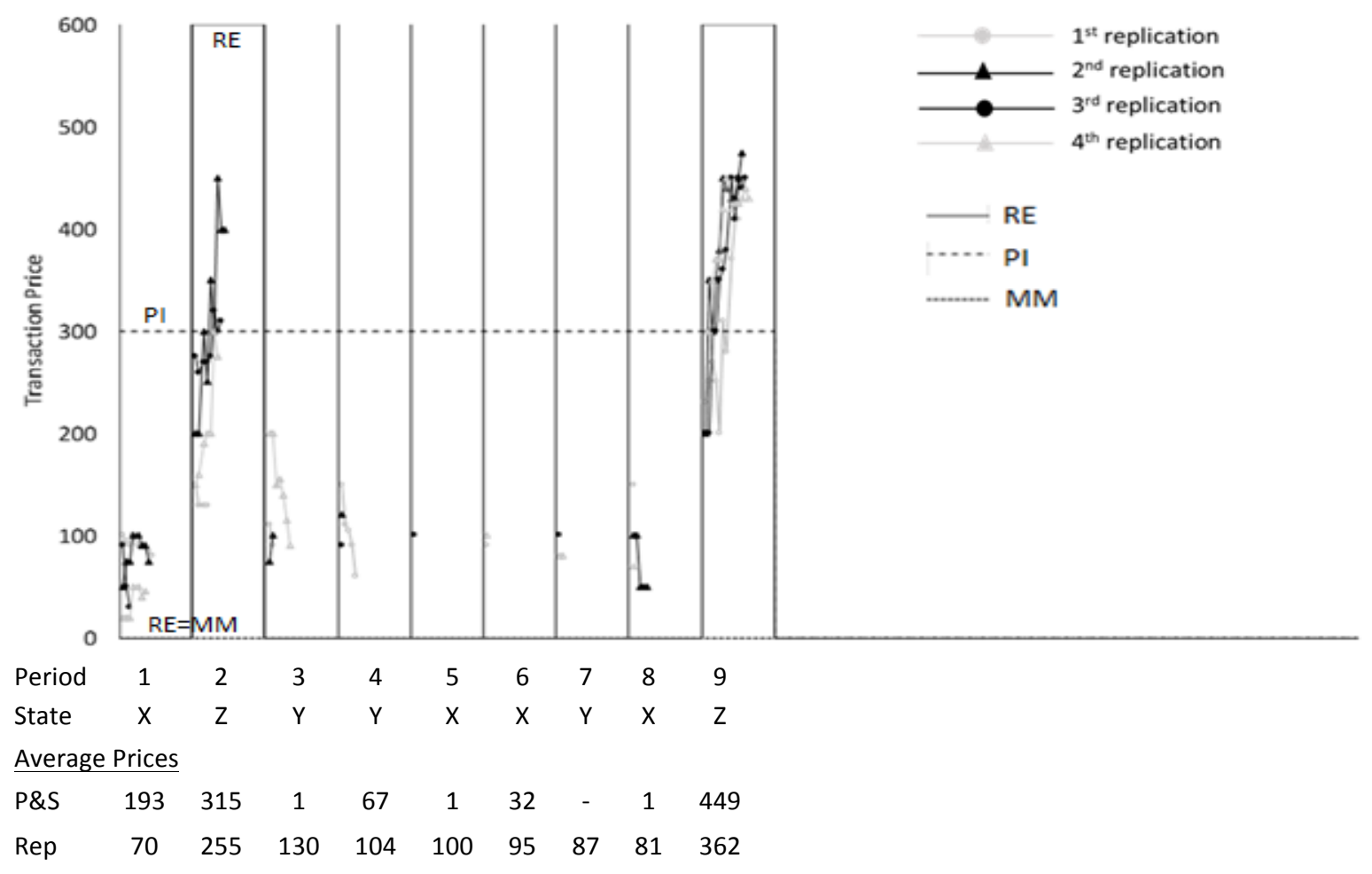


Figure 3. Prices in Market 7 Sessions

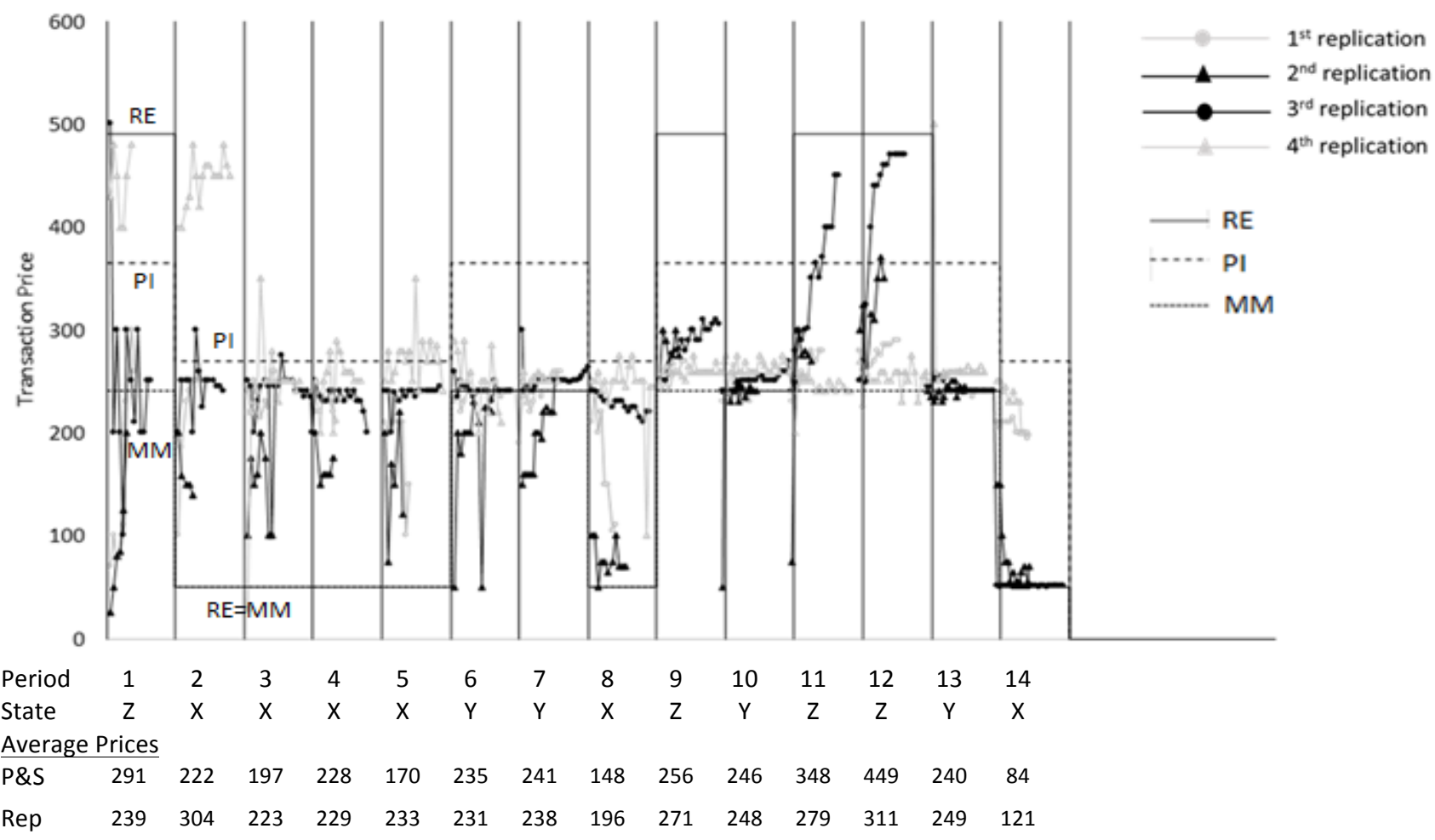

Figure 4. Prices in Market 8 Sessions

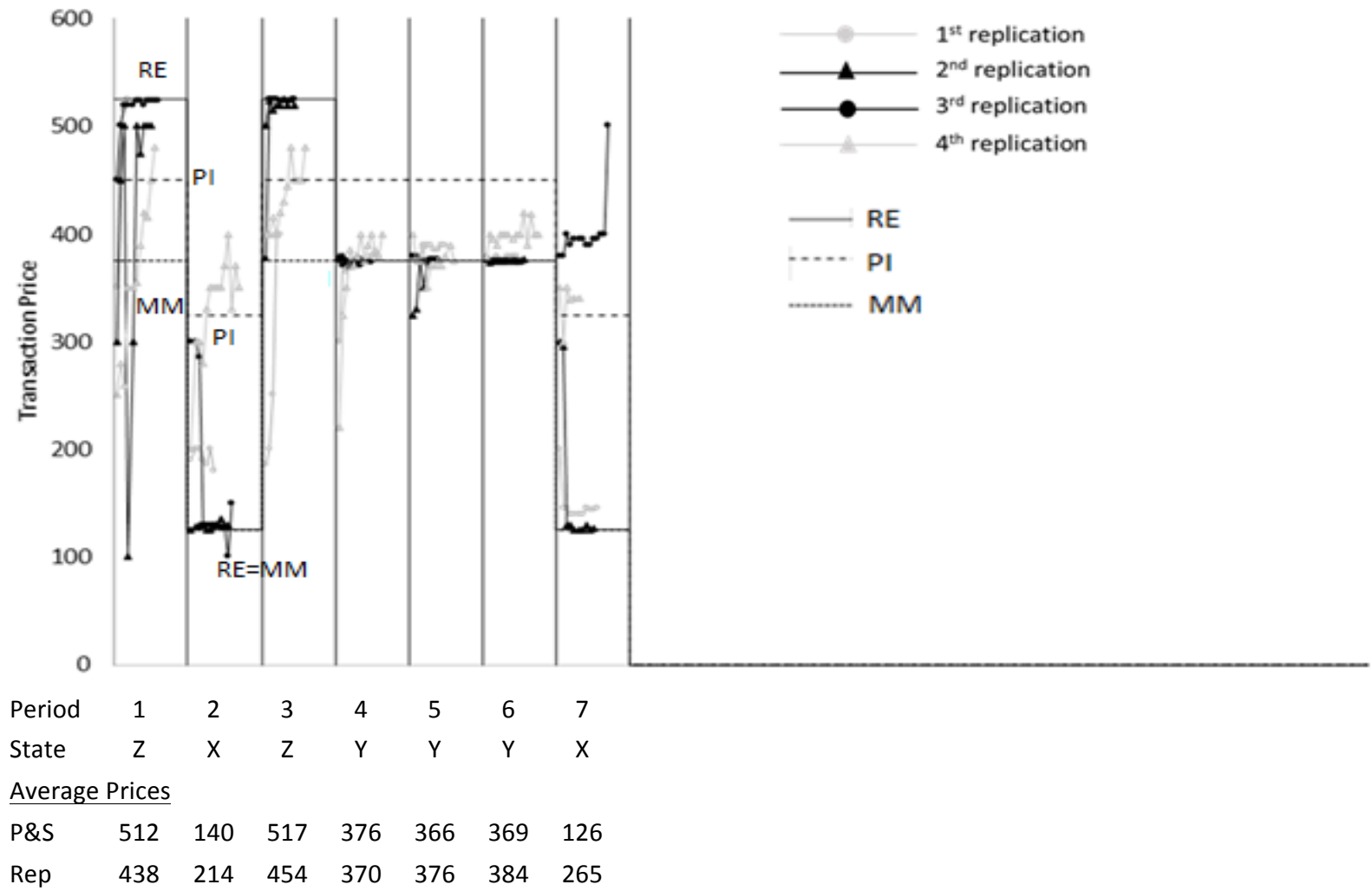




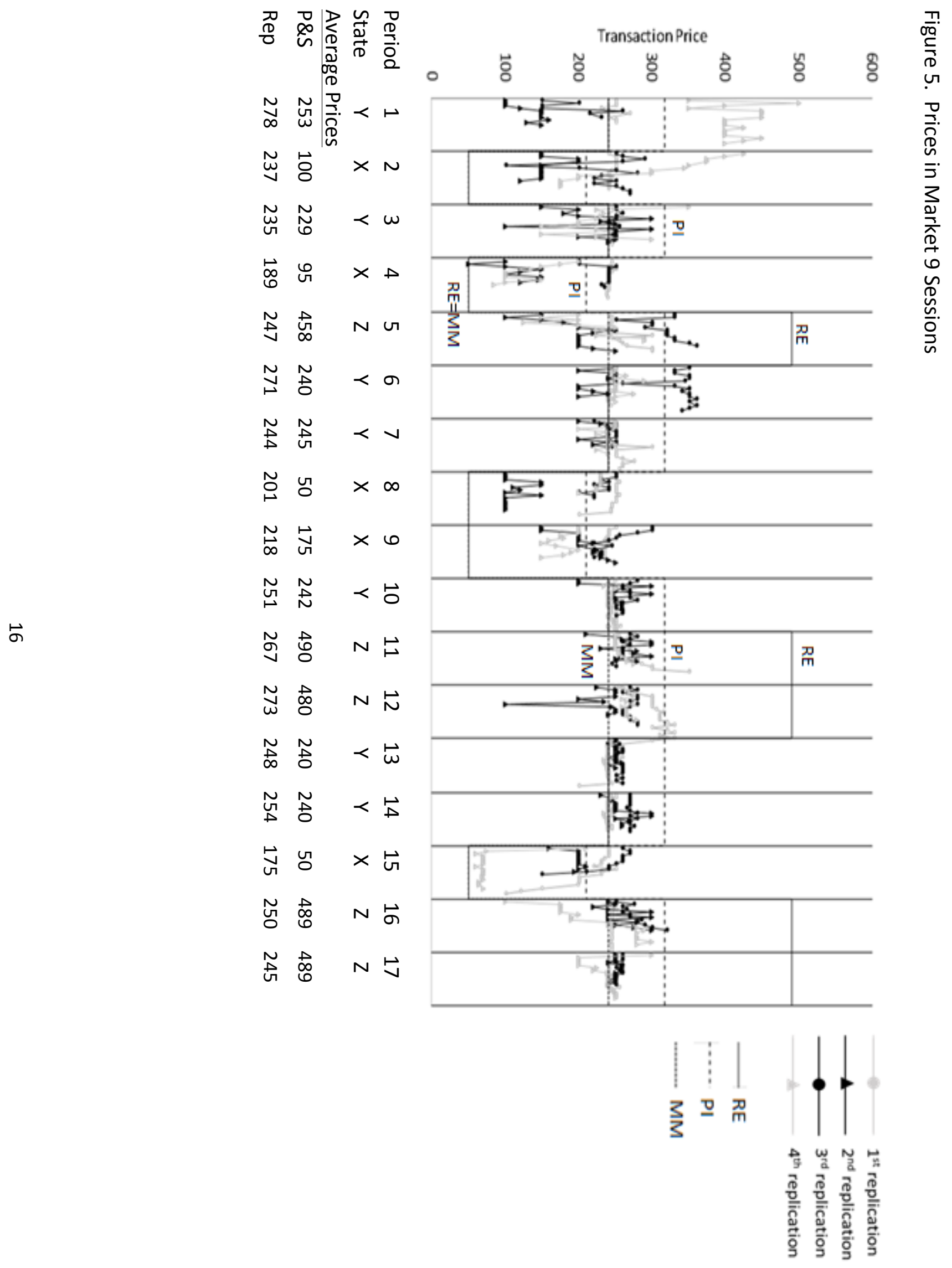


Prices

Regarding prices, we assess the performance of the respective models using the three criteria proposed by P\&S: mean absolute price deviation (hereafter, MAD), log odds and percentage of convergent price changes. Following $P \& S$, we give information aggregation its "best chance" by only considering the last occurrence of each of the possible asset values for each market (i.e., periods 7, 8, and 9 for Market 4 and periods 14, 15, and 17 for Market 9). To assess the mean absolute price deviation (MAD), we calculate the average across sessions of the absolute difference between the price and the value predicted by each model ( $\mathrm{PI}, \mathrm{RE}$ and $\mathrm{MM}$ ) (see Appendix A or P\&S). For each session, this value is calculated as:

$$
M A D:=\underset{i, t}{\operatorname{average}}\left|p_{i, t}-m_{t}\right|
$$

where $i$ represents a transaction, $t$ denotes a period in which a state was realized for the last time, $p_{i, t}$ corresponds to the transaction price, and $m_{t}$ is the predicted price under the appropriate model. Thus, the mean absolute price deviation is computed as the average over all transactions in the last occurrence of each state of nature for each session. The second measure used in P\&S is log odds, which we calculated by regressing, for each model, the observed prices in given session on the predicted price under that model (using price data from the periods corresponding to the last occurrence of each state of nature). We then recovered the log likelihood value under the normality assumption. A third measure of information aggregation developed in $\mathrm{P} \& \mathrm{~S}$ is the percentage of convergent price changes. The $N+1^{\text {st }}$ transaction is considered to be convergent if its price is no further from the selected model's prediction than the price of the previous transaction, $N$. That is, the $N+1^{\text {st }}$ transaction is deemed convergent if:

$$
\left|p_{N+1, t}-m_{t}\right| \leq\left|p_{N, t}-m_{t}\right|
$$

where $p_{N}$ is the market price of the $N^{\text {th }}$ transaction. For each model, the ratio of convergent price changes to the total number of transactions over the three periods in which a state was realized for the last time per session is reported in Table $3 .^{8}$

An overview of Table 3 shows that the RE model does not outperform the other two models, regardless of the criterion or the series we consider. The RE model actually underperforms the $\mathrm{PI}$ model on the criterion of mean absolute price deviation ( $p$-value $=0.048$ ) when considering, as in P\&S, all sessions from Series B and C. But, the RE model does outperform $\mathrm{PI}$ on the criterion of percentage of convergent price changes even though RE does not significantly outperform MM for this criterion. No model stands out with regard to the criterion of log odds. If we take Series B and C separately, we obtain a similar finding; RE does not perform

\footnotetext{
${ }^{8}$ As an initial transaction is required to determine if the subsequent transaction is convergent, we utilize the total number of transactions minus three (since we consider three market periods) as the denominator in this ratio.
} 
significantly better than both of the other two models according to any of the three criteria. This contradicts Conclusion 2 in P\&S (p. 1104) according to which "In markets with a complete set of state contingent securities (Series B) and in markets with a single security with uniform dividends (Series $\mathrm{C}$ ) the RE model price predictions outperform both PI and MM."

Finding 1: We are unable to replicate the finding that the RE model outperforms the PI and MM models in terms of predicting prices in the Series B and C markets.

\section{Allocations}

As in P\&S, we proceed by assessing whether the allocation of shares at the end of each period (corresponding to the last occurrence of each state of nature) is consistent with the allocation predicted by each model (see Appendix A or P\&S), and we compare the fit across models. The allocation statistic is determined via the formula:

$$
A=\left(\sum_{c \in C} \sum_{i \in I_{c}} n_{i, c}-\bar{n}_{c}\right) /\left(\sum_{c \in C} \sum_{i \in I_{c}} n_{i, c}^{(m)}-\bar{n}_{c}\right) x 100
$$

where $n_{i, c}$ represents the number of shares of certificates $c$ held by investor $i$ at the end of the market, $I_{c}$ denotes the set of traders predicted to hold the asset, $C$ denotes the set of certificates in the market, $n_{i, c}^{(m)}$ corresponds to the number of shares predicted to be held by investor $i$ according to model $m$, and $\bar{n}$ is set to the average number of shares initially held by all investors in $I_{c}$. This ratio is then averaged over the three periods in which each state was realized for the last time. The values for each replicate of each session are shown in Table 4 and can be compared to Table IV in P\&S.

In line with our previous findings on price predictions, the RE model does not outperform either PI or MM. These findings contradict Conclusion 3 in P\&S (p. 1106) according to which "In all series, allocations aggregated over the final occurrence of each state are more accurately predicted by the RE model than either the PI or MM." However, when looking at Series B only we do find that the RE model outperforms PI which is the only alternative model for which we have a prediction.

Finding 2: We are unable to replicate the finding that RE outperforms $\mathrm{PI}$ and $\mathrm{MM}$ in predicting final asset allocations in the Series B and C markets, though RE outperforms PI when evaluating Series B markets separately. 


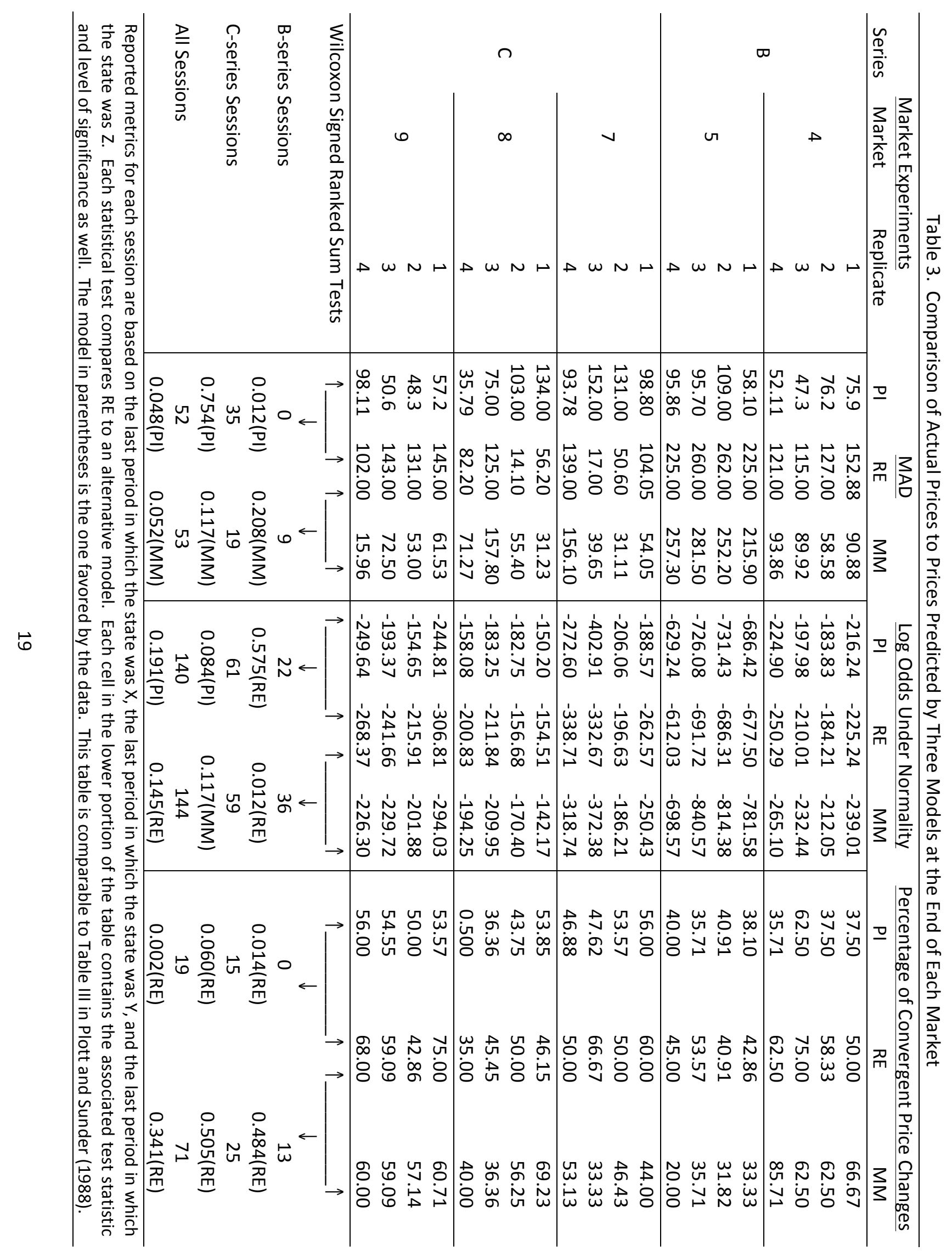


Table 4. Comparison of Actual Allocations with the Allocations Predicted by Three Models Criterion: Percent of Predicted Flow of Securities that Actually Occurred at the End of Each Market

\begin{tabular}{|c|c|c|c|c|c|}
\hline \multicolumn{3}{|c|}{ Market Experiments } & \multicolumn{3}{|c|}{$\underline{\text { Models }}$} \\
\hline Series & Market & Replicate & $\mathrm{PI}$ & $\mathrm{RE}$ & $\mathrm{MM}$ \\
\hline \multirow{8}{*}{ B } & \multirow{4}{*}{4} & 1 & 4.44 & 12.5 & No Prediction \\
\hline & & 2 & 3.89 & 12.5 & No Prediction \\
\hline & & 3 & 3.89 & 22.92 & No Prediction \\
\hline & & 4 & 9.45 & 12.50 & No Prediction \\
\hline & \multirow{4}{*}{5} & 1 & 14.88 & 45.83 & No Prediction \\
\hline & & 2 & 16.67 & 50.00 & No Prediction \\
\hline & & 3 & 20.83 & 70.83 & No Prediction \\
\hline & & 4 & 14.83 & 52.08 & No Prediction \\
\hline \multirow{12}{*}{ C } & \multirow{4}{*}{7} & 1 & 31.94 & No Prediction & 41.67 \\
\hline & & 2 & 27.78 & No Prediction & 25.00 \\
\hline & & 3 & 9.21 & No Prediction & 27.08 \\
\hline & & 4 & 38.89 & No Prediction & 47.92 \\
\hline & \multirow{4}{*}{8} & 1 & 5.56 & No Prediction & 45.84 \\
\hline & & 2 & 38.89 & No Prediction & 37.50 \\
\hline & & 3 & 52.78 & No Prediction & 29.17 \\
\hline & & 4 & 30.56 & No Prediction & 49.99 \\
\hline & \multirow{4}{*}{9} & 1 & 40.28 & No Prediction & 52.09 \\
\hline & & 2 & 26.39 & No Prediction & 27.09 \\
\hline & & 3 & 23.61 & No Prediction & 25.00 \\
\hline & & 4 & 43.06 & No Prediction & 60.42 \\
\hline \multirow{2}{*}{\multicolumn{3}{|c|}{ Wilcoxon Rank Sum Tests }} & $\uparrow$ & $\uparrow \uparrow \uparrow$ & $\uparrow$ \\
\hline & & & & & $\downarrow$ \\
\hline \multicolumn{3}{|c|}{ B-series Sessions } & 0.0 & \multicolumn{2}{|r|}{ Undefined } \\
\hline \multicolumn{3}{|c|}{ C-series Sessions } & Und & & Undefined \\
\hline \multirow{2}{*}{\multicolumn{3}{|c|}{ All Sessions }} & & & 135 \\
\hline & & & 0.2 & & $0.487(\mathrm{MM})$ \\
\hline
\end{tabular}

Reported metrics for each session are based on the last period in which the state was $X$, the last period in which the state was $Y$, and the last period in which the state was $Z$, as applicable. Each statistical test compares RE to an alternative model. Each cell in the lower portion of the table contains the associated test statistic and level of significance as well. The model in parentheses is the one favored by the data based on the median. This table is comparable to Table IV in Plott and Sunder (1988). However, P\&S report that a Wilcoxon Signed Rank Sum Test is used, but that test is not defined for any comparison between RE and another model except for a test between PI and RE in Series-B Markets. The test statistic for such a test would be 0 based on our data with a $p$-value of 0.012 with the data favoring RE.

\section{Profits}

Finally, we compare the models' predictions on the distribution of profits. In Table 5 (comparable to Table $V$ in $P \& S$ ), we display the weighted sum of the squared deviation between 
the average earnings of a trader of a given type and information and the average predicted earnings, given the trader's type and information, averaged over the three periods corresponding to the last occurrence of each state of nature. ${ }^{9}$ In line with our previous findings on price and allocation predictions, we do not find that the RE model outperforms both alternatives; although, it significantly outperforms PI. These findings lead us to reject Conclusion 4 in P\&S (p. 1108) according to which "In all series the RE model is a significantly better predictor of the distribution of profits than either the PI model or the MM model." On a positive note, when studied separately RE is shown to outperform the other two models in Series C markets. However, the profit prediction of the RE model for Series C markets is for every trader in the market to receive the same profit. Hence the RE model predicts that each person receives the average profit, which may drive some of the apparent success. A model that predicted no one ever placed a bid or ask in the market would have done equally well on this criterion for Series $C$.

Finding 3: We are unable to replicate the finding that RE outperforms $\mathrm{PI}$ and $\mathrm{MM}$ in predicting traders' profits in the Series B and C markets, though RE outperforms PI and MM when evaluating Series $\mathrm{C}$ markets separately.

As a final note, experience does not seem to encourage information aggregation in our sample, as evidence for information aggregation was not found despite using for each session, as in P\&S, only the data for the last occurrence of each possible state of nature. ${ }^{10}$ Moreover, we do not find support for the RE model prediction when restricting our analysis to the 8 sessions in which the market was populated by experienced traders (see Appendix C for the analysis of Markets 5 and 8 combined).

\section{Discussion}

Whether markets are able to aggregate dispersed information is a fundamental question in Economics (Hayek, 1945). Because testing the strong-form efficiency of markets is not possible using archival data (Fama, 1991), experimental markets were critical to test whether such efficiency was achievable. The breakthrough design proposed by P\&S thus made the efficient markets hypothesis falsifiable. Although the original findings in P\&S show that it is possible for markets to achieve strong-form efficiency, our data show these findings are indeed fragile. Moreover, neither the existence of contingent claims nor common dividend values seem to be

\footnotetext{
${ }^{9}$ Each model is silent with regards to which specific traders of a given type with a given piece of information should hold the assets. That is, if two traders are of the type and information predicted to purchase two assets being offered for sale, the models are silent as to whether one trader will buy both or each will buy one. Our approach thus removes profit deviations that are due to the allocation of assets within a given class of trader.

${ }^{10}$ The general conclusions do not differ if data from every trading period is used.
} 
sufficient to facilitate information aggregation. Our results thus call for a revival of research examining the institutional and behavioral factors that can give rise to efficient markets.

Table 5. Comparison of Actual Distribution of Profits to Distribution Predicted by Three Models Criterion: Squared Sum of Deviations from the Mean Across Investors at the End of Each Market

\begin{tabular}{|c|c|c|c|c|c|}
\hline \multicolumn{3}{|c|}{ Market Experiments } & \multicolumn{3}{|c|}{ Models } \\
\hline Series & Market & Replicate & $\mathrm{PI}$ & RE & $\mathrm{MM}$ \\
\hline \multirow{8}{*}{ B } & \multirow{4}{*}{4} & 1 & 8644.73 & 638.31 & 245.51 \\
\hline & & 2 & 8782.26 & 684.59 & 262.73 \\
\hline & & 3 & 8932.91 & 686.13 & 283.23 \\
\hline & & 4 & 8302.06 & 604.81 & 245.21 \\
\hline & \multirow{4}{*}{5} & 1 & 24266.25 & 2721.85 & 1949.32 \\
\hline & & 2 & 25360.95 & 2474.61 & 2182.88 \\
\hline & & 3 & 24838.72 & 1912.72 & 1989.12 \\
\hline & & 4 & 25273.38 & 2858.71 & 2068.18 \\
\hline \multirow{12}{*}{ C } & \multirow{4}{*}{7} & 1 & 4281.22 & 49.62 & 3422.95 \\
\hline & & 2 & 4752.76 & 7.30 & 3787.30 \\
\hline & & 3 & 5473.51 & 36.55 & 4783.22 \\
\hline & & 4 & 3408.69 & 201.63 & 2894.96 \\
\hline & \multirow{4}{*}{8} & 1 & 819.42 & 51.95 & 145.95 \\
\hline & & 2 & 729.95 & 3.95 & 42.61 \\
\hline & & 3 & 272.03 & 1220.29 & 1578.69 \\
\hline & & 4 & 952.74 & 13.57 & 401.57 \\
\hline & \multirow{4}{*}{9} & 1 & 1489.34 & 1197.76 & 951.10 \\
\hline & & 2 & 2969.62 & 95.46 & 3762.12 \\
\hline & & 3 & 2224.53 & 256.19 & 2989.52 \\
\hline & & 4 & 2133.63 & 361.39 & 1971.72 \\
\hline \multirow{2}{*}{\multicolumn{3}{|c|}{ Wilcoxon Signed Ranked Sum Tests }} & $\uparrow$ & $\uparrow \uparrow \uparrow$ & $\uparrow$ \\
\hline & & & $\downarrow$ & & $\downarrow$ \\
\hline \multirow{2}{*}{\multicolumn{3}{|c|}{ B-series Sessions }} & 36 & & 35 \\
\hline & & & $0.012(\mathrm{RE})$ & & $0.017(\mathrm{MM})$ \\
\hline \multirow{2}{*}{\multicolumn{3}{|c|}{ C-series Sessions }} & 73 & & 75 \\
\hline & & & $0.008(R E)$ & & $0.005(R E)$ \\
\hline \multirow{2}{*}{\multicolumn{3}{|c|}{ All Sessions }} & 205 & & 139 \\
\hline & & & $<0.001(\mathrm{RE})$ & & $0.204(R E)$ \\
\hline
\end{tabular}

Reported metrics for each session are based on the last period in which the state was $\mathrm{X}$, the last period in which the state was $Y$, and the last period in which the state was $Z$, as applicable. Each statistical test compares RE to an alternative model. Each cell in the lower portion of the table contains the associated test statistic and level of significance as well. The model in parentheses is the one favored by the data. This table is comparable to Table V in Plott and Sunder (1988). 


\section{References}

Anderson, L. and C. Holt (1997) "Information Cascades in the Laboratory," American Economic Review, 847-862.

Arrow, Kenneth, Robert Forsythe, Michael Gorham, Robert Hahn, Robin Hanson, John Ledyard, Saul Levmore, Robert Litan, Paul Milgrom, Forrest Nelson, George Neumann, Marco Ottaviani, Thomas Schelling, Robert Shiller, Vernon Smith, Erik Snowberg, Cass Sunstein, Paul Tetlock, Philip Tetlock, Hal Varian, Justin Wolfers, and Eric Zitzewitz (2008): "The Promise of Prediction Markets," Science, 320, 877-888.

Biais, Bruno, Denis Hilton, Karine Mazurier and Sébastien Pouget (2005) "Judgmental Overconfidence, Self-Monitoring and Trading Performance in an Experimental Financial Market," The Review of Economic Studies 72(2), 287-312.

Bossaerts, P. (2009) "What Decision Neuroscience Teaches us About Financial Decision Making," Annual Review of Financial Economics 1, 383-404.

Camerer C., Dreber A., E. Forsell et al. (2016) "Evaluating Replicability of Laboratory Experiments in Economics," Science 351, 1433-1436.

Camerer C., Dreber A., E. Forsell et al. (2018) "Evaluating Replicability of Social Science Experiments in Nature and Science between 2010 and 2015," Nature Human Behaviour 2, 637644.

Chamberlin, E. (1948) “An Experimental Imperfect Market” The Journal of Political Economy 56, 95-108.

Chen, K. and C. Plott (2002) "Information Aggregation Mechanisms, Concept, Design and Field Implementation," Social Science Working Paper1131, California Institute of Technology.

Corgnet, B., Deck, C., DeSantis, M. and D. Porter (2018) "Information (Non) Aggregation in Markets with Costly Signal Acquisition," Journal of Economic Behavior \& Organization 154, 286320.

Corgnet, B., DeSantis, M. and D. Porter (2015) "Revisiting Information Aggregation in Asset Markets: Reflective Learning \& Market Efficiency," ESI Working Paper 15-15.

Corgnet, B., DeSantis, M. and D. Porter (2019) "The Distribution of Information and the Price Efficiency of Markets", In Press Journal of Economic Dynamics and Control.

Cowgill, B., J. Wolfers, and E. Zitzewitz (2009) "Using Prediction Markets to Track Information Flows: Evidence from Google," in Auctions, Market Mechanisms and Their Applications Volume 14, eds. Sanmay Das, Michael Ostrovsky, David Pennock, and Boleslaw Szymanksi, Springer: Berlin. 
Deck, C. and D. Porter (2013) "Prediction Markets in the Laboratory," Journal of Economic Surveys 27(3), 589-603.

Fama, E. (1970) "Efficient Capital Markets: A Review of Theory and Empirical Work," The Journal of Finance 25(2), 383-417.

Fama, E. (1991) “Efficient Capital Markets: II,” The Journal of Finance 46(5), 1575-1617.

Fama, E. (2008) "A Brief History of the Efficient Market Hypothesis," American Finance Association speech.

Forsythe, R. and R. Lundholm (1990) "Information Aggregation in an Experimental Market," Econometrica 58 (2), 309-348.

Frydman, C., Barberis, N., Camerer, C., Bossaerts, P. and A. Rangel (2014) “Using Neural Data To Test a Theory of Investor Behavior: An Application to Realization Utility," Journal of Finance 69, 907-946.

Gillen, B., C. Plott, and M. Shum (2017) "A Pari-Mutuel-Like Mechanism for Information Aggregation: A Field Test inside Intel," Journal of Political Economy 125(4), 1075-1099.

Hanson, R., Oprea, R. and D. Porter (2006) "Information Aggregation and Manipulation in an Experimental Market," Journal of Economic Behavior and Organization 60, 449-459.

Hayek, F. (1945) "The Use of Knowledge in Society," American Economic Review 35(4), 519-530.

Huber, J., M. Angerer and M. Kirchler (2011) "Experimental Asset Markets with Endogenous Choice of Costly Asymmetric Information," Experimental Economics 14(2), 223-240.

Frydman, C., Barberis, N., Camerer, C., Bossaerts, P. and A. Rangel (2014) “Using Neural Data to Test a Theory of Investor Behavior: An Application to Realization Utility," Journal of Finance 69 (2), 907-946.

Lintner, J. (1969) "The Aggregation of Investor's Diverse Judgments And Preferences In Purely Competitive Security Markets," Journal of Financial and Quantitative Analysis 4, 347-400.

Noussair, C. and S. Tucker (2013) "A Collection of Surveys on Market Experiments," Wiley Blackwell.

Page, L. and C. Siemroth (2017) "An Experimental Analysis of Information Acquisition In Prediction Markets," Games and Economic Behavior 101, 354-378.

Page, L. and C. Siemroth (2018) "How Much Information is Incorporated in Financial Asset Prices? Experimental Evidence," Working Paper.

Shiller, R. (2015) “Irrational Exuberance," 3rd edition, Princeton University Press.

Shleifer, A. (2000) “Clarendon Lectures: Inefficient Markets," Oxford University Press. 
Smith V. (1962) "An Experimental Study of Competitive Market Behavior," The Journal of Political Economy 70, 111-137.

Thaler, R. (2005) "Advances in Behavioral Finance," Volume II (Roundtable Series in Behavioral Economics), Princeton: Princeton University Press.

Thaler, R. (2015) “Misbehaving: The Making of Behavioral Economics," New York: W. W. Norton \& Company.

Veiga, H. and M. Vorsatz (2010) "Information Aggregation in Experimental Asset Markets in The Presence of a Manipulator," Experimental Economics 13(4), 379-398. 


\section{Appendices}

\section{Appendix A. Prediction tables (P\&S)}

Price predictions

Table A.1. Price predictions for each model.

\begin{tabular}{|c|c|c|c|c|}
\hline \multirow{2}{*}{ Market } & \multirow{2}{*}{ Model } & \multicolumn{3}{|c|}{ True State } \\
\hline & & $x$ & $Y$ & Z \\
\hline & $\mathrm{RE}$ & 230 & 0 & 0 \\
\hline \multirow[t]{3}{*}{$4 X$} & PI & 146 & 146 & 101 \\
\hline & MM & 0 & 0 & 0 \\
\hline & $\mathrm{RE}$ & 0 & 160 & 0 \\
\hline \multirow[t]{3}{*}{$4 Y$} & $\mathrm{PI}$ & 58 & 58 & 49 \\
\hline & MM & 0 & 0 & 0 \\
\hline & $\mathrm{RE}$ & 0 & 0 & 300 \\
\hline \multirow[t]{3}{*}{$4 Z$} & $\mathrm{PI}$ & 169 & 208 & 208 \\
\hline & MM & 0 & 0 & 0 \\
\hline & $\mathrm{RE}$ & 460 & 0 & 0 \\
\hline \multirow[t]{3}{*}{$5 X$} & $\mathrm{PI}$ & 230 & 230 & 230 \\
\hline & MM & 0 & 0 & 0 \\
\hline & $\mathrm{RE}$ & 0 & 320 & 0 \\
\hline \multirow[t]{3}{*}{$5 Y$} & $\mathrm{PI}$ & 160 & 160 & 160 \\
\hline & MM & 0 & 0 & 0 \\
\hline & $\mathrm{RE}$ & 0 & 0 & 600 \\
\hline \multirow[t]{3}{*}{$5 Z$} & PI & 300 & 300 & 300 \\
\hline & MM & 0 & 0 & 0 \\
\hline & $\mathrm{RE}$ & 50 & 240 & 590 \\
\hline \multirow[t]{3}{*}{7} & PI & 270 & 365 & 365 \\
\hline & MM & 50 & 240 & 240 \\
\hline & $\mathrm{RE}$ & 125 & 375 & 450 \\
\hline \multirow[t]{3}{*}{8} & $\mathrm{PI}$ & 325 & 450 & 450 \\
\hline & MM & 125 & 375 & 375 \\
\hline & $\mathrm{RE}$ & 50 & 240 & 490 \\
\hline \multirow[t]{2}{*}{9} & $\mathrm{PI}$ & 210 & 317 & 317 \\
\hline & $\mathrm{MM}$ & 50 & 240 & 240 \\
\hline
\end{tabular}




\section{Allocation predictions}

Table A.2. Allocation predictions for each model.

Type (I, II and III) and clue of traders who should hold the certificates according to a given model.

\begin{tabular}{|c|c|c|c|c|}
\hline \multirow{2}{*}{ Market } & \multirow{2}{*}{ Model } & \multicolumn{3}{|c|}{ True State } \\
\hline & & $x$ & $\mathrm{Y}$ & Z \\
\hline \multirow{3}{*}{$4 X$} & RE & II & - & - \\
\hline & $\mathrm{PI}$ & II (Not Z) & II (Not Z) & II (Not Y) \\
\hline & MM & ----------------- & predictions- & ---------- \\
\hline \multirow{3}{*}{$4 Y$} & $\mathrm{RE}$ & - & III & - \\
\hline & $\mathrm{PI}$ & III (Not Z) & III (Not Z) & III (Not X) \\
\hline & MM & - & predictions- & ---------- \\
\hline \multirow{3}{*}{$4 Z$} & $\mathrm{RE}$ & - & - & I \\
\hline & $\mathrm{PI}$ & I (Not Y) & I (Not X) & I (Not X) \\
\hline & MM & ------------------- & predictions- & - \\
\hline \multirow{3}{*}{$5 X$} & $\mathrm{RE}$ & II & - & - \\
\hline & $\mathrm{PI}$ & II & II (Not Z) & II (Not Y) \\
\hline & MM & ---------------- & predictions- & ------------ \\
\hline \multirow{3}{*}{$5 Y$} & $\mathrm{RE}$ & - & III & - \\
\hline & $\mathrm{PI}$ & III (Not Z) & III & III (Not X) \\
\hline & MM & --------------------' & predictions- & ---------- \\
\hline \multirow{3}{*}{$5 Z$} & $\mathrm{RE}$ & - & - & I \\
\hline & $\mathrm{PI}$ & I (Not Y) & I (Not X) & 1 \\
\hline & MM & -------------------- & predictions- & --------- \\
\hline \multirow{3}{*}{7} & $\mathrm{RE}$ & & All (no trade & \\
\hline & $\mathrm{PI}$ & Not $Y$ & Not $Y$ & Not $Y$ \\
\hline & MM & All (no trade) & Not X & Not X \\
\hline \multirow{3}{*}{8} & $\mathrm{RE}$ & & All (no trade & \\
\hline & $\mathrm{PI}$ & Not $Y$ & Not X & Not X \\
\hline & MM & All (no trade) & Not X & Not X \\
\hline \multirow{3}{*}{9} & $\mathrm{RE}$ & & All (no trade & \\
\hline & $\mathrm{PI}$ & Not $Y$ & Not $Y$ & Not $Y$ \\
\hline & $\mathrm{MM}$ & All (no trade) & Not X & Not X \\
\hline
\end{tabular}




\section{Appendix B. Complete Set of Instructions}

\section{Steps to Run Hand Run Information Aggregation Markets}

Prior to Experiment

1. Set up Bingo cage with correct number of balls and have a coin available.

2. Have market program set up on podium computer (not projected). Have document camera for Market Operation Example.

3. Place a numbered (1 through 12 ) notecard at each position asking for subject name and student id.

4. Place a) calculator, b) pen, c) Trader Sign, and d) Subject Name and ID Card at each position.

5. Place a) Instruction Set 1, b) Response Form for random draw training, and c) Clue Sheets. Note: a) and c) are market specific.

Subject Sign in

6. Subjects consent

7. Subjects fill out Subject Name and ID card and RA signs them into the market program

\section{Experiment}

8. Auctioneer reads Script 0

9. Auctioneer reads Script 1

10. Conduct 10 Drawings with replacement

11. Collect Response Forms

12. Auctioneer reads Script 2

13. Auctioneer conducts 10 practice rounds with clues.
a) draw a ball
b) flip coin
c) call out row (=practice number) and column (based on draw and flip)
d) put ball back in bingo cage

14. Handout a) Instruction Set 3, b) Profit Sheet, and c) Year 1 Information and Record Sheet. Note: b) is market specific while a) and c) are market and trader specific.

15. Auctioneer reads Instruction Set 3. "__ is read as blank because this is private information for each trader.

16. Auctioneer goes through the Market Operation Example.

Order of call should be Trader \#, Action, (Market), Price. (Market) is only for contingent claims.

17. Conduct Market Year

a) Handout Year Y record and Information Sheet (already done for Year 1). Note: This is market and trader specific

b) Announce Clue row and column. Row is $10+y e a r$. Column indicated by "pickme."

c) Start 7 minute market year.

d) Repeat a-c until last Year completed. Number of Years differs by Market. For Market 4, return to Step 14 after Year 9.

18. Collect all papers. Calculate total payments $=$ Trading Profit + Prediction Payment from $12+$ Show up Payment.

19. Pay and dismiss subjects. 


\section{Set 0 Script}

This is an experiment in the economics of market decision making. Various research foundations have provided funds for this research. The instructions are simple, and if you follow them carefully and make good decisions, you might earn a considerable amount of money which will be paid to you in cash. In this experiment we are going to simulate a market in which you will buy and sell certificates in a sequence of market years.

This experiment has four steps:

(1) training with the mechanism used to draw states of nature,

(2) training with the mechanism used to provide clues about the state of nature,

(3) explanation of procedures and rules of the market,

(4) conduct of markets for several years. 


\section{Set 1 Script}

Instruction Set 1 [Market 4]

Each year we draw a ball from a bingo cage containing twenty balls numbered one through twenty. If the ball drawn is numbered one through seven, outcome of the draw is called $x$; if a ball numbered eight through eleven is drawn, the outcome is called $\mathrm{y}$; if a ball numbered twelve through twenty is drawn, the outcome is called $z$.

You have to predict the outcome of each draw before it is announced. If your prediction is correct, you win \$0.50; if wrong, you lose \$0.20. Before the first draw is made, record your prediction by circling either $\mathrm{x}$ or $\mathrm{y}$ or $\mathrm{z}$ in the first row of the enclosed sheet. After you have encircled one letter, the outcome will be announced and you should record the announced outcome in the blank space on the same row of the table. If your prediction is correct, circle the amount shown in the Win column, otherwise circle the amount shown in the Lose column.

Once you have recorded your prediction you must not make a change; any erasure will invalidate your prediction. At the end, add up your total winnings and losses and record the difference (net winnings or losses) at the bottom right corner of the sheet. 


\section{States of Nature Training Sheet}

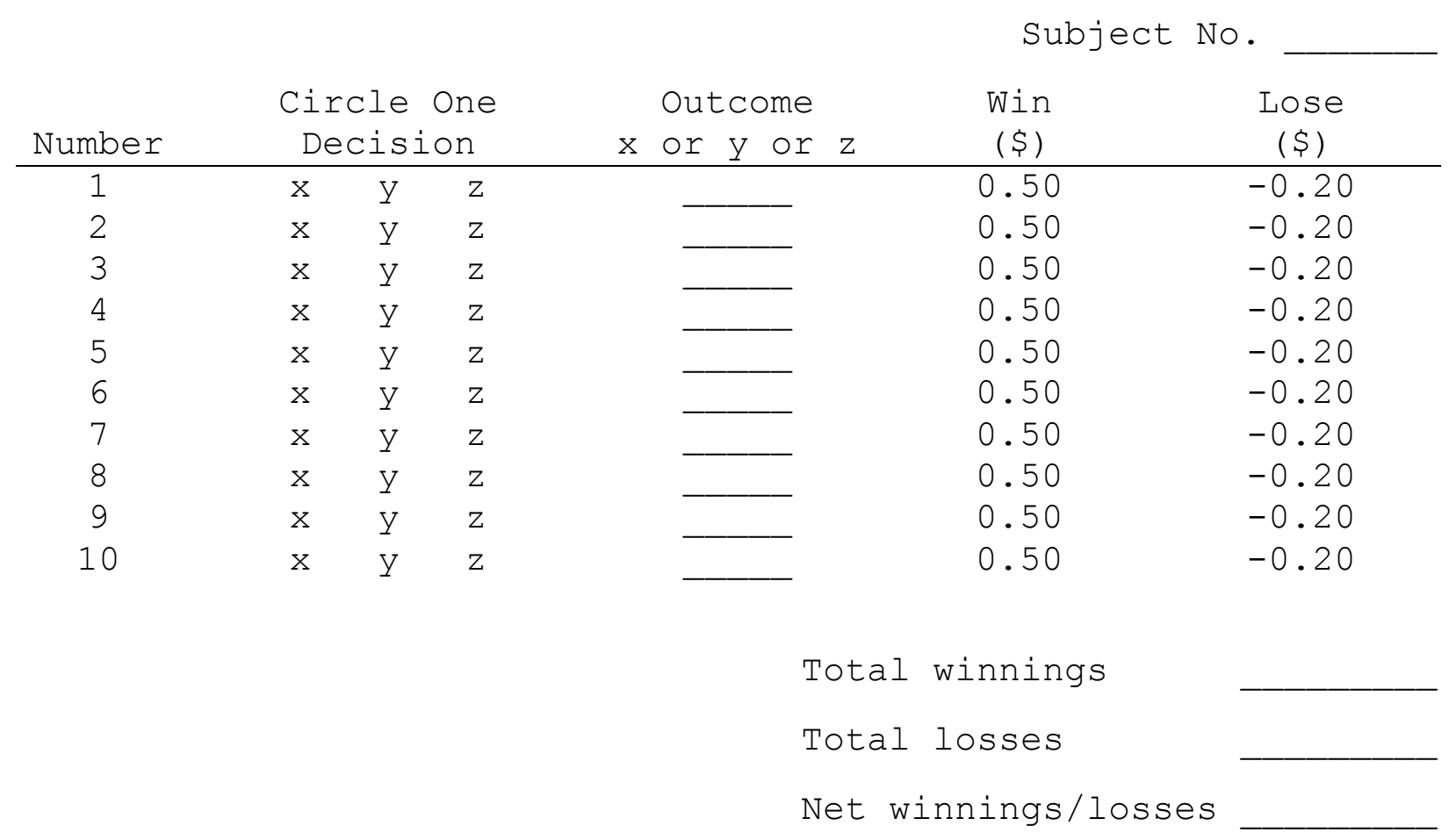




\section{Instruction Set 1 [Market 9]}

Each year we draw a ball from a bingo cage containing twenty balls numbered one through twenty. If the ball drawn is numbered one through seven, outcome of the draw is called $\mathrm{x}$; if a ball numbered eight through sixteen is drawn, the outcome is called $y$; if a ball numbered seventeen through twenty is drawn, the outcome is called $z$.

You have to predict the outcome of each draw before it is announced. If your prediction is correct, you win \$0.50; if wrong, you lose \$0.20. Before the first draw is made, record your prediction by circling either $\mathrm{x}$ or $\mathrm{y}$ or $\mathrm{z}$ in the first row of the enclosed sheet. After you have encircled one letter, the outcome will be announced and you should record the announced outcome in the blank space on the same row of the table. If your prediction is correct, circle the amount shown in the Win column, otherwise circle the amount shown in the Lose column.

Once you have recorded your prediction you must not make a change; any erasure will invalidate your prediction. At the end, add up your total winnings and losses and record the difference (net winnings or losses) at the bottom right corner of the sheet. 


\section{Instruction Set 1 [Markets 5, 7 \& 8]}

Each year we draw a ball from a bingo cage containing thirty balls numbered one through thirty. If the ball drawn is numbered one through ten, outcome of the draw is called $x$; if a ball numbered eleven through twenty is drawn, the outcome is called $y$; if a ball numbered twentyone through thirty is drawn, the outcome is called $z$.

You have to predict the outcome of each draw before it is announced. If your prediction is correct, you win \$0.50; if wrong, you lose \$0.20. Before the first draw is made, record your prediction by circling either $\mathrm{x}$ or $\mathrm{y}$ or $\mathrm{z}$ in the first row of the enclosed sheet. After you have encircled one letter, the outcome will be announced and you should record the announced outcome in the blank space on the same row of the table. If your prediction is correct, circle the amount shown in the Win column, otherwise circle the amount shown in the Lose column.

Once you have recorded your prediction you must not make a change; any erasure will invalidate your prediction. At the end, add up your total winnings and losses and record the difference (net winnings or losses) at the bottom right corner of the sheet. 


\section{Set 2 Script}

You have each received a clue sheet. Do not reveal this sheet to anyone.

You will use this clue sheet to receive a clue about what the outcome is in a particular year. Therefore, we will now go through some examples of how to use the clue sheet.

Each year the experimenter will draw a bingo ball from the cage to determine if the outcome is $x$ or $y$ or $z$. The experimenter will then call out a row and column. You will use this row and column to determine your clue. The other investors will use their own sheets to determine their clues.

If the outcome is $x$ then there are two possible clues: not $y$ and not $z$

If the outcome is $y$ then there are two possible clues: not $x$ and not $z$

If the outcome is $z$ then there are two possible clues: not $x$ and not $y$

Everyone's sheet is different. Which of the two possible clues that you receive is determined randomly. The clues that other investors receive are also determined randomly. But the clues are distributed in such a way that exactly half of all investors receive one of the two possible clues and the other half receive the other possible clue.

We will now practice with the clue sheet. 
Clue Sheet [Each clue sheet was trader and Market Specific]

Clue Sheet

Trader \#:

\begin{tabular}{|c|c|c|c|c|c|c|}
\hline & \multicolumn{6}{|c|}{ Columns } \\
\hline & 1 & 2 & 3 & 4 & 5 & 6 \\
\hline 1 & not z & not $x$ & not y & not z & not y & not $x$ \\
\hline 2 & not z & not $x$ & not $x$ & not y & not z & not $y$ \\
\hline 3 & not $x$ & not y & not $x$ & not z & not y & not z \\
\hline 4 & not z & not y & not y & not $x$ & not z & not $x$ \\
\hline 5 & not z & not $x$ & not z & not y & not y & not $x$ \\
\hline 6 & not $x$ & not $x$ & not y & not y & not z & not z \\
\hline 7 & not $x$ & not $x$ & not y & not z & not z & not $y$ \\
\hline 8 & not y & not z & not y & not $x$ & not $x$ & not z \\
\hline 9 & not y & not z & not $x$ & not $x$ & not z & not $y$ \\
\hline 10 & not z & not y & not z & not y & not $x$ & not $x$ \\
\hline 11 & not $x$ & not z & not z & not y & not $x$ & not $y$ \\
\hline 12 & not z & not z & not y & not y & not $x$ & not $x$ \\
\hline 13 & not y & not $x$ & not $x$ & not z & not y & not z \\
\hline 14 & not z & not z & not $x$ & not y & not y & not $x$ \\
\hline 15 & not $x$ & not y & not y & not z & not z & not $x$ \\
\hline 16 & not y & not $x$ & not $x$ & not z & not z & not $y$ \\
\hline 17 & not z & not z & not y & not y & not $x$ & not $x$ \\
\hline 18 & not $x$ & not y & not z & not $x$ & not z & not $y$ \\
\hline 19 & not y & not z & not z & not $x$ & not y & not $x$ \\
\hline 20 & not y & not y & not z & not z & not $x$ & not $x$ \\
\hline 21 & not z & not y & not $x$ & not z & not y & not $x$ \\
\hline 22 & not $x$ & not z & not y & not z & not $x$ & not $y$ \\
\hline 23 & not $x$ & not $x$ & not z & not y & not y & not $z$ \\
\hline 24 & not $x$ & not $x$ & not y & not z & not y & not $z$ \\
\hline 25 & not z & not y & not $x$ & not z & not $x$ & not $y$ \\
\hline 26 & not z & not y & not $x$ & not z & not y & not $x$ \\
\hline 27 & not $x$ & not $x$ & not y & not z & not y & not $z$ \\
\hline 28 & not y & not $x$ & not $x$ & not z & not z & not $y$ \\
\hline 29 & not $x$ & not y & not z & not z & not $x$ & not $y$ \\
\hline 30 & not y & not y & not $x$ & not z & not z & not $x$ \\
\hline
\end{tabular}




\section{Set 3 Script}

Instructions Set 3 Script [Single Asset]

General. - This is an experiment in the economics of market decision making. Various research foundations have provided funds for this research. The instructions are simple, and if you follow them carefully and make good decisions, you might earn a considerable amount of money which will be paid to you in cash.

In this experiment we are going to simulate a market in which you will buy and sell certificates in a sequence of market years. Attached to the instructions you will find a sheet, labeled information and record sheet, which helps determine the value to you of any decisions you might make. You are not to reveal this information to anyone. It is your own private information.

The type of currency used in this market is francs. All trading and earnings will be in terms of francs. Each franc is worth to you. Do not reveal this number to anyone. At the end of the experiment your francs will be converted to dollars at this rate, and you will be paid in dollars. Notice that the more francs you earn the more dollars you earn.

\section{Specific Instructions}

Your profits come from two sources-from collecting certificate earnings on all certificates you hold at the end of the year and from buying and selling certificates. During each market year you are free to purchase or sell as many certificates as you wish, provided you follow the rules below. For each certificate you hold at the end of the year you will be given one of the three numbers of francs listed on row 19 of your information and record sheet. Note that earnings may be different for different investors. The method by which one of the three numbers is selected each year is explained later in these instructions. Compute your total certificate earnings for a period by multiplying the earnings per certificate by the number of certificates held. That is, (number of certificates held) $x$ (earnings per certificate) $=$ total certificate earnings. Suppose, for example, that you hold five certificates at the end of year 1 . If for that period your earnings are ___ francs per certificate (i.e., the number selected from row 19 is

) then your total certificate earnings in the year would be $5 \mathrm{x}$ $=$ francs. This number should be recorded on row 19 at the end of the year.

Sales from your certificate holdings increase your francs on hand by the amount of the sale price. Similarly, purchases reduce your francs on hand by the amount of the purchase price. Thus you can gain or lose money on the purchase and resale of certificates. At the end of each year all your holdings are automatically sold to the experimenter at a price of 0 . At the beginning of each year you are provided with an initial holding of certificates. This is recorded on row 0 of the year's information and record sheet. You may sell these if you wish or you may 
hold them. If you hold a certificate, then you receive "earnings per certificate" at the end of the year.

In addition, at the beginning of each year you are provided with an initial amount of francs on hand. This is also recorded on row 0 of each year's information and record sheet. You may keep this if you wish or you may use it to purchase certificates.

Thus at the beginning of each year you are endowed with holdings of certificates and francs on hand. You are free to buy and sell certificates as you wish according to the rules below. Your francs on hand at the end of a year are determined by your initial amount of francs on hand, earnings on certificate holdings at the end of the year, and by gains and losses from purchases and sales of certificates. All francs on hand at the end of a year in excess of francs are yours to keep. These are your profits for the year.

\section{Information about Dividends}

Whether the dividend you receive from the certificates you hold is the $x$-dividend shown on row 19 or the $y$-dividend on row 19 or the z-dividend on row 19 depends on the draw of an outcome from a bingo cage. If the outcome is $x$ the dividend is the $x$-dividend. If the outcome is $y$ the dividend is the $y$-dividend. If the outcome is $z$ the dividend is the $z$-dividend. The outcomes were determined before the experiment began by drawing a ball from a bingo cage in a manner similar to what was described earlier.

As a reminder, each year there is a _35_\% chance that the outcome is $x$; a _ 45 _\% chance that the outcome is $y$; and a_20_\% chance that the outcome is $z$.

At the beginning of each year, before trading starts, each investor will receive a clue using the clue sheets you have already received.

\section{Trading and Recording Rules}

(1) All transactions are for one certificate at a time. After each of your sales or purchases you must record the TRANSACTION PRICE in the appropriate column depending on the nature of the transaction. The first transaction is recorded on row (1), and succeeding transactions are recorded on subsequent rows.

(2) After each transaction you must calculate and record your new holdings of certificates and your new francs on hand. Your holdings of certificates may go below zero. Your francs on hand may never go below zero.

(3) At the end of the year record your total certificate earnings in the last column of row 19. If you have negative certificate holdings, you receive no dividends, and you must pay a penalty of 300 francs plus the highest transaction price during the period, for each 
certificate you are short. Compute your end of period totals on row 20 by listing certificate holdings and adding total certificate earnings to your francs on hand.

(4) At the end of the year, subtract from your francs on hand the amount listed in row 21 and enter this new amount on row 22. This is your profit for the market year and is yours to keep. At the end of each market year, record this number on your profit sheet.

(5) At the end of the experiment add up your total profit on your profit sheet and enter this sum on row 22 of your profit sheet. To convert this number into dollars, multiply by the number on row 23 and record the product on row 24. The experimenter will pay you this amount of money.

Market organization. - The market for these certificates is organized as follows. The market will be conducted in a series of years. Each period lasts for seven minutes. Anyone wishing to purchase a certificate is free to raise his or her hand and make a verbal bid to buy one certificate at a specified price, and anyone with certificates to sell is free to accept or not accept the bid. Likewise, anyone wishing to sell a certificate is free to raise his or her hand and make a verbal offer to sell one certificate at a specified price. If a bid or offer is accepted, a binding contract has been closed for a single certificate, and the contracting parties will record the transaction on their information and record sheets. Any ties in bids or acceptance will be resolved by random choice. Except for the bids and their acceptance, you are not to speak to any other subject. There are likely to be many bids that are not accepted, but you are free to keep trying. You are free to make as much profit as you can. 


\section{Instructions Set 3 Script [Contingent Claims]}

General. - This is an experiment in the economics of market decision making. Various research foundations have provided funds for this research. The instructions are simple, and if you follow them carefully and make good decisions, you might earn a considerable amount of money which will be paid to you in cash.

In this experiment we are going to simulate a market in which you will buy and sell certificates in a sequence of market years. Attached to the instructions you will find a sheet, labeled information and record sheet, which helps determine the value to you of any decisions you might make. You are not to reveal this information to anyone. It is your own private information.

The type of currency used in this market is francs. All trading and earnings will be in terms of francs. Each franc is worth to you. Do not reveal this number to anyone. At the end of the experiment your francs will be converted to dollars at this rate, and you will be paid in dollars. Notice that the more francs you earn the more dollars you earn.

\section{Specific Instructions}

Your profits come from two sources-from collecting certificate earnings on all certificates you hold at the end of the year and from buying and selling certificates. During each market year you are free to purchase or sell as many certificates as you wish, provided you follow the rules below. There are three types of certificate: $x$-certificate, $y$-certificate, and $z$-certificate. For each certificate of a given type that you hold at the end of the year you will be given either the number of francs listed on row 19 of your information and record sheet for that certificate type or 0 . Note that earnings may be different for different investors. The method by which one of the two numbers for each certificate type is selected each year is explained later in these instructions. Compute your total certificate earnings for a period by multiplying the earnings per certificate of a given type by the number of certificates of that type held and then summing these three amounts. That is, (number of $x$-certificates held) $x$ (earnings per $x$-certificate) + (number of $y$-certificates held) $x$ (earnings per $y$-certificate) + (number of $z$-certificates held) $x$ (earnings per $z$-certificate) $=$ total certificate earnings. Suppose, for example, that you hold five $x$-certificates at the end of year 1 . If for that period your earnings are francs per $x$ certificate (i.e., the number for $x$-certificates from row 19 is ) then your total $x$-certificate earnings in the year would be $5 x$ francs. Suppose you hold $4 y$-certificates and $3 z$ certificates at the end of year 1 . If for that period your earnings are 0 francs per certificate for $y$ certificates and $z$-certificates then your total $y$-certificate earnings in the year would be $4 \times 0=0$ francs and your total $z$-certificate earnings in the year would be $3 \times 0=0$ francs. Your total certificate earnings would be __ $+0+0=$ francs. This number should be recorded on row 19 at the end of the year. 
Sales from your certificate holdings increase your francs on hand by the amount of the sale price. Similarly, purchases reduce your francs on hand by the amount of the purchase price. Thus you can gain or lose money on the purchase and resale of certificates. At the end of each year all your holdings are automatically sold to the experimenter at a price of 0 . At the beginning of each year you are provided with an initial holding of certificates. This is recorded on row 0 of the year's information and record sheet. You may sell these if you wish or you may hold them. If you hold a certificate, then you receive "earnings per certificate" at the end of the year.

In addition, at the beginning of each year you are provided with an initial amount of francs on hand. This is also recorded on row 0 of each year's information and record sheet. You may keep this if you wish or you may use it to purchase certificates.

Thus at the beginning of each year you are endowed with holdings of certificates and francs on hand. You are free to buy and sell certificates as you wish according to the rules below. Your francs on hand at the end of a year are determined by your initial amount of francs on hand, earnings on certificate holdings at the end of the year, and by gains and losses from purchases and sales of certificates. All francs on hand at the end of a year in excess of francs are yours to keep. These are your profits for the year.

\section{Information about Dividends}

Whether the dividend you receive from the certificates of a given type you hold is the amount shown on row 19 or 0 depends on the draw of an outcome from a bingo cage. If the outcome is $x$ then $x$-certificates receive the $x$-dividend shown on row 19 while $y$-certificates and $z$ certificates each earn 0 . If the outcome is $y$ then $y$-certificates receive the $y$-dividend shown on row 19 while $x$-certificates and $z$-certificates each earn 0 . If the outcome is $z$ then $z$ certificates receive the $z$-dividend shown on row 19 while $x$-certificates and $y$-certificates each earn 0 . The outcomes were determined before the experiment began by drawing a ball from a bingo cage in a manner similar to what was described earlier.

As a reminder, each year there is a _35_\% chance that the outcome is $x$; a _20_\% chance that the outcome is $y$; and a _ 45 _\% chance that the outcome is $z$.

At the beginning of each year, before trading starts, each investor will receive a clue using the clue sheets you have already received.

\section{Trading and Recording Rules}

(6) All transactions are for one certificate of a given type at a time. After each of your sales or purchases you must record the TRANSACTION PRICE in the appropriate column 
depending on the nature of the transaction. The first transaction is recorded on row (1), and succeeding transactions are recorded on subsequent rows.

(7) After each transaction you must calculate and record your new holdings of certificates and your new francs on hand. Your holdings of certificates of any type may go below zero. Your francs on hand may never go below zero.

(8) At the end of the year record your total certificate earnings in the last column of row 19. If you have negative certificate holdings of a type, you receive no dividends for that type, and you must pay a penalty of 300 francs plus the highest transaction price for that type during the period, for each certificate you are short. Compute your end of period totals on row 20 by listing certificate holdings and adding total certificate earnings to your francs on hand.

(9) At the end of the year, subtract from your francs on hand the amount listed in row 21 and enter this new amount on row 22. This is your profit for the market year and is yours to keep. At the end of each market year, record this number on your profit sheet.

(10) At the end of the experiment add up your total profit on your profit sheet and enter this sum on row 22 of your profit sheet. To convert this number into dollars, multiply by the number on row 23 and record the product on row 24 . The experimenter will pay you this amount of money.

Market organization. - The market for these certificates is organized as follows. The market will be conducted in a series of years. Each period lasts for seven minutes. Anyone wishing to purchase a certificate of a given type is free to raise his or her hand and make a verbal bid to buy one certificate of a given type at a specified price, and anyone with certificates of the given type to sell is free to accept or not accept the bid. Likewise, anyone wishing to sell a certificate of a given type is free to raise his or her hand and make a verbal offer to sell one certificate of a given type at a specified price. If a bid or offer is accepted, a binding contract has been closed for a single certificate, and the contracting parties will record the transaction on their information and record sheets. Any ties in bids or acceptance will be resolved by random choice. Except for the bids and their acceptance, you are not to speak to any other subject. There are likely to be many bids that are not accepted, but you are free to keep trying. You are free to make as much profit as you can. 
Name

PROFIT SHEET

\begin{tabular}{|c|c|c|}
\hline Row & Market Year & Profit \\
\hline 1 & 1 & \\
\hline 2 & 2 & \\
\hline 3 & 3 & \\
\hline 4 & 4 & \\
\hline 5 & 5 & \\
\hline 6 & 6 & \\
\hline 7 & 7 & \\
\hline 8 & 8 & \\
\hline 9 & 9 & \\
\hline 10 & 10 & \\
\hline 11 & 11 & \\
\hline 12 & 12 & \\
\hline 13 & 13 & \\
\hline 14 & 14 & \\
\hline 15 & 15 & \\
\hline 16 & 16 & \\
\hline 17 & 17 & \\
\hline 18 & 18 & \\
\hline 19 & 19 & \\
\hline 20 & 20 & \\
\hline 21 & & \\
\hline 22 & Total profit (in francs) & \\
\hline 23 & Dollars per franc & $0.003^{11}$ \\
\hline 24 & Total dollars profit & \\
\hline
\end{tabular}

${ }^{11}$ This exchange rate varies across markets. 


\section{INFORMATION AND RECORD SHEET [Single Asset]}

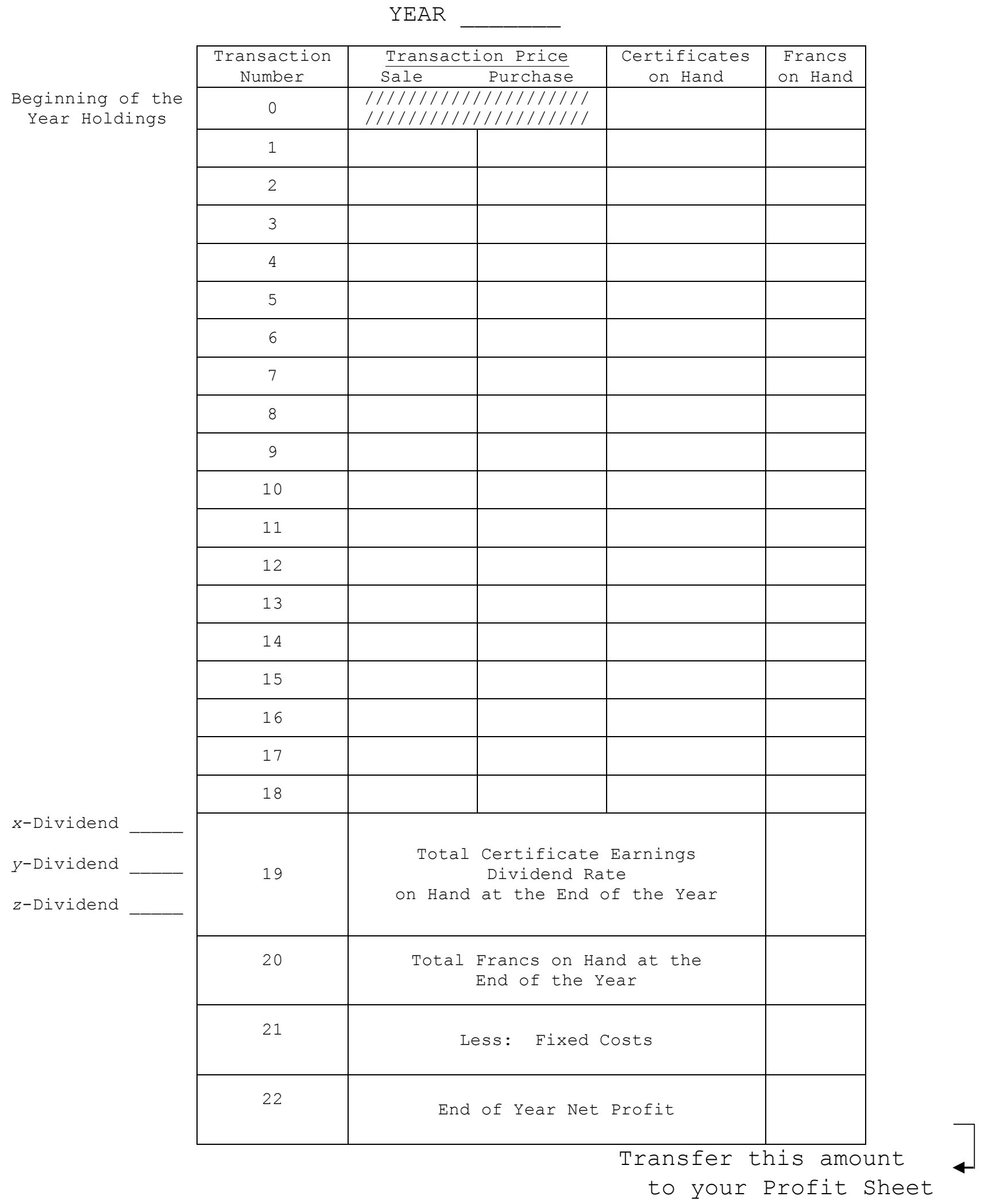


INFORMATION AND RECORD SHEET [Contingent Claims]

Beginning of the Year Holdings

x-Dividend YEAR

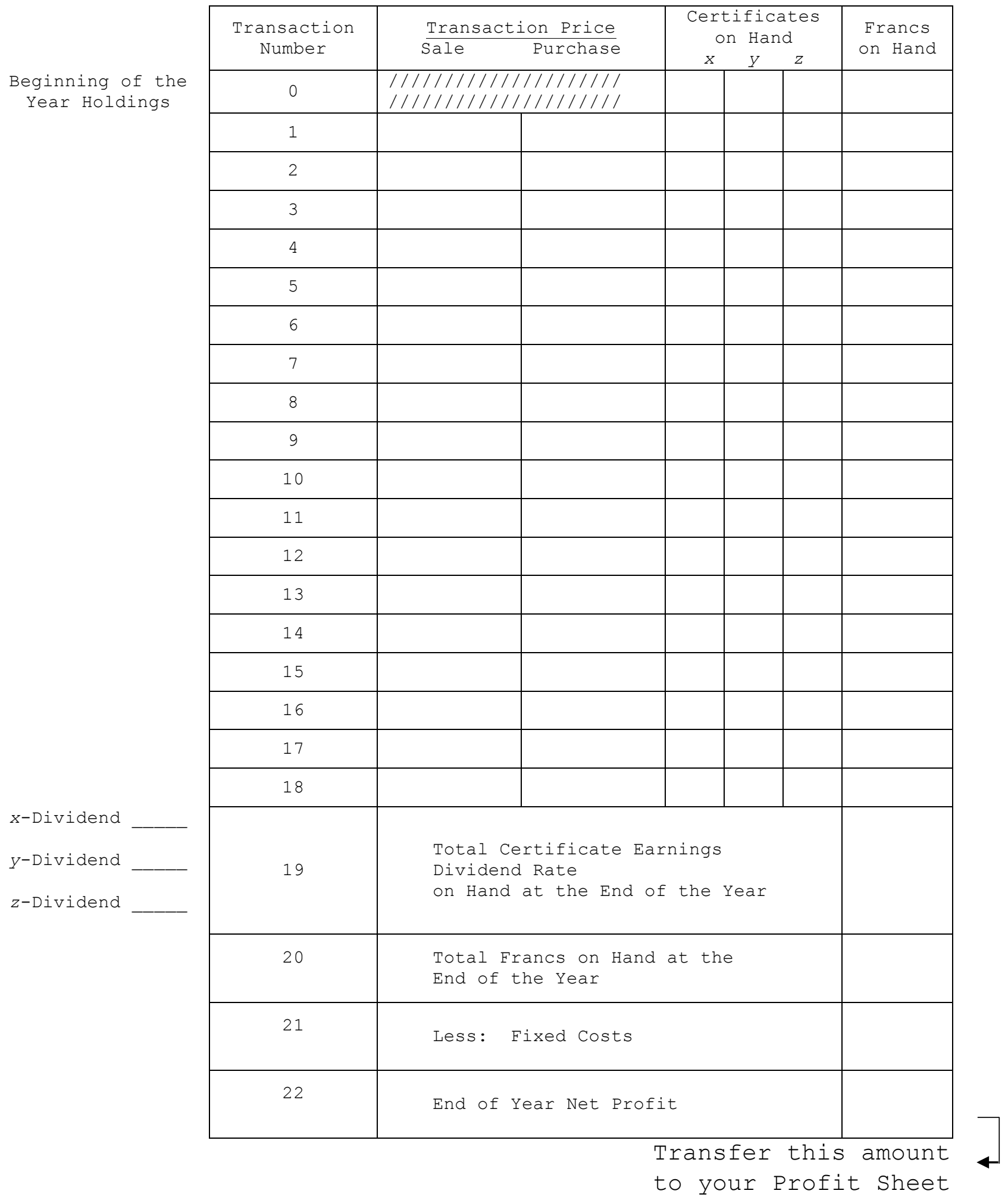




\section{Demonstration of Market [Single Asset]}

We will now go through a demonstration of how the market will work.

The auctioneer will announce the market is open.

Suppose that Trader 13 wants to offer to buy a certificate at a price of 25 . Trader 13 would raise her paddle and the auctioneer would call on her saying something like "Trader 13." Trader 13 would then respond with "Bid of 25." The auctioneer will repeat the order: "Trader 13 Bids 25." This will be recorded on the board. [The order is marked on the board.]

Now suppose that Trader 14 wants to offer to sell a certificate at a price of 500 . Trader 14 should raise his paddle. When the auctioneer calls on Trader 14, Trader 14 should announce "Ask 500." The auctioneer will repeat "Trader 14 Asks 500." This will then be recorded on the board. [The order is marked on the board.]

This process will continue as long as someone wants to improve on the currently standing bid or ask or accept the standing bid or ask. For example, Trader 13 may raise her paddle and after being called state "Bid of 100." The auctioneer will repeat "Trader 13 Bids 100" and this will be marked on the board. [The order is marked on the board.] Notice that you can improve upon your own bid or ask.

If Trader 15 is willing to sell at 100, the current standing bid, Trader 15 can raise her paddle. When called upon Trader 15 will state "Accept Bid 100." The auctioneer will repeat that "Trader 15 Accepts Bid of 100." At this point Trader 13 and 15 have traded a single certificate and this will be reflected on the board by circling the accepted bid. [Circle the accepted bid on the board and write Trader 15 on the line as the seller.]

Trader 13 will record on her Information and Record sheet that she purchased a certificate by writing the price in the Purchase column in the row corresponding to Transaction 1 . She will then update her Certificates on Hand and Francs on Hand. Similarly, Trader 15 will record on her Information and Record sheet that she sold a certificate by writing the price in the Sale column in the row corresponding to Transaction 1. She will then update her Certificates on Hand and Francs on Hand.

A line will be drawn across the market record on the board indicating that all of the previous bids and asks are no longer available. The auctioneer will then invite new bids or asks.

Trader 13 may state an Ask of 600 .

Trader 14 may state an Ask of 542.

Trader 16 may state a Bid of 33 .

Trader 17 may state a Bid of 35 .

Trader 16 may state a bid of 40. 
Trader 17 may state a Bid of 60.

Trader 14 may state an Ask 500.

Trader 15 may Accept the Bid of 60.

At this point, the bid of 60 is circled and Traders 17 would record the price of 60 under Purchase in the row for Transaction 1. Trader 17 would then update his Certificates on Hand and Francs on Hand. Notice that for Trader 15 this would be her second transaction, so she would record the Sale price on the row for Transaction 2 and then update the remainder of the row.

A line will be drawn across the market record on the board indicating that all of the previous bids and asks are no longer available and the auctioneer will again invite new bids or asks. This process continues until 7 minutes have passed at which point no more bids, asks, or acceptance can be made.

Suppose there are no more transactions involving Trader 15 in the market year. If the state is $\mathrm{Y}$, given the fictitious values in this example, Trader 15 would complete their Information and Record Sheet as follows:

Total Certificate Earnings in Row 19 would be: $\quad 8 * 100=800$

Total Francs on Hand in Row 20 would be: 20,160

End of Year Net Profit in Row 22 would be: $800+20,160-20,000=960$. 


\section{Demonstration of Market [Contingent Claims]}

We will now go through a demonstration of how the market will work.

The auctioneer will announce the market is open.

Suppose that Trader 13 wants to offer to buy an X certificate at a price of 25 . Trader 13 would raise her paddle and the auctioneer would call on her saying something like "Trader 13." Trader 13 would then respond with "Bid on X of 25." The auctioneer will repeat the order: "Trader 13 Bid on X of 25." This will be recorded on the board. [The order is marked on the board.]

Now suppose that Trader 14 wants to offer to sell an X certificate at a price of 500 . Trader 14 should raise his paddle. When the auctioneer calls on Trader 14, Trader 14 should announce "Ask for X of 500." The auctioneer will repeat "Trader 14 Ask for X of 500." This will then be recorded on the board. [The order is marked on the board.]

This process will continue as long as someone wants to improve on the currently standing bid or ask or accept the standing bid or ask. For example, Trader 13 may raise her paddle and after being called state "Bid on X of 100." The auctioneer will repeat "Trader 13 Bid on X of 100" and this will be marked on the board. [The order is marked on the board.] Notice that you can improve upon your own bid or ask.

If Trader 15 is willing to sell $X$ at 100 , the current standing bid, Trader 15 can raise her paddle. When called upon Trader 15 will state "Accept Bid on X of 100." The auctioneer will repeat that "Trader 15 Accepts Bid on X of 100." At this point Trader 13 and 15 have traded a single X certificate and this will be reflected on the board by circling the accepted bid. [Circle the accepted bid on the board and write Trader 15 on the line as the seller.]

Trader 13 will record on her Information and Record sheet that she purchased an X certificate by writing the price in the Purchase column in the row corresponding to Transaction 1 . She will then update her Certificates on Hand and Francs on Hand. Similarly, Trader 15 will record on her Information and Record sheet that she sold an X certificate by writing the price in the Sale column in the row corresponding to Transaction 1. She will then update her Certificates on Hand and Francs on Hand.

A line will be drawn across the $X$ market record on the board indicating that all of the previous bids and asks for $X$ certificates are no longer available. The auctioneer will then invite new bids or asks.

Trader 13 may state an Ask for $\mathrm{X}$ of 600.

Trader 14 may state an Ask for $Y$ of 542.

Trader 17 may state a Bid on Y of 35 
Trader 16 may state a Bid on X of 33.

Trader 16 may state a bid on $\mathrm{X}$ of 40 .

Trader 17 may state a Bid on Y of 60.

Trader 14 may state an Ask on X for 500 .

Trader 15 may Accept the Bid on Y of 60.

At this point, the bid of 60 for $Y$ is circled and Trader 17 would record the price of 60 under Purchase in the row for Transaction 1. Trader 17 would then update all of his Certificates on Hand and Francs on Hand. Notice that for Trader 15 this would be her second transaction, so she would record the Sale price on the row for Transaction 2 and then update the remainder of the row.

A line will be drawn across the market record for $Y$ on the board indicating that all of the previous bids and asks for $Y$ are no longer available and the auctioneer will again invite new bids or asks. Notice that the bids and asks for $X$ are still available. This process continues until 7 minutes have passed at which point no more bids, asks, or acceptance can be made.

Suppose there are no more transactions involving Trader 15 in the market year. If the state is $\mathrm{Y}$, given the fictitious values in this example, Trader 15 would complete their Information and Record Sheet as follows:

Total Certificate Earnings in Row 19 would be: $\quad 9 * 0+9 * 100+10 * 0=900$

Total Francs on Hand in Row 20 would be: 20,160

End of Year Net Profit in Row 22 would be: $900+20,160-20,000=1,060$. 


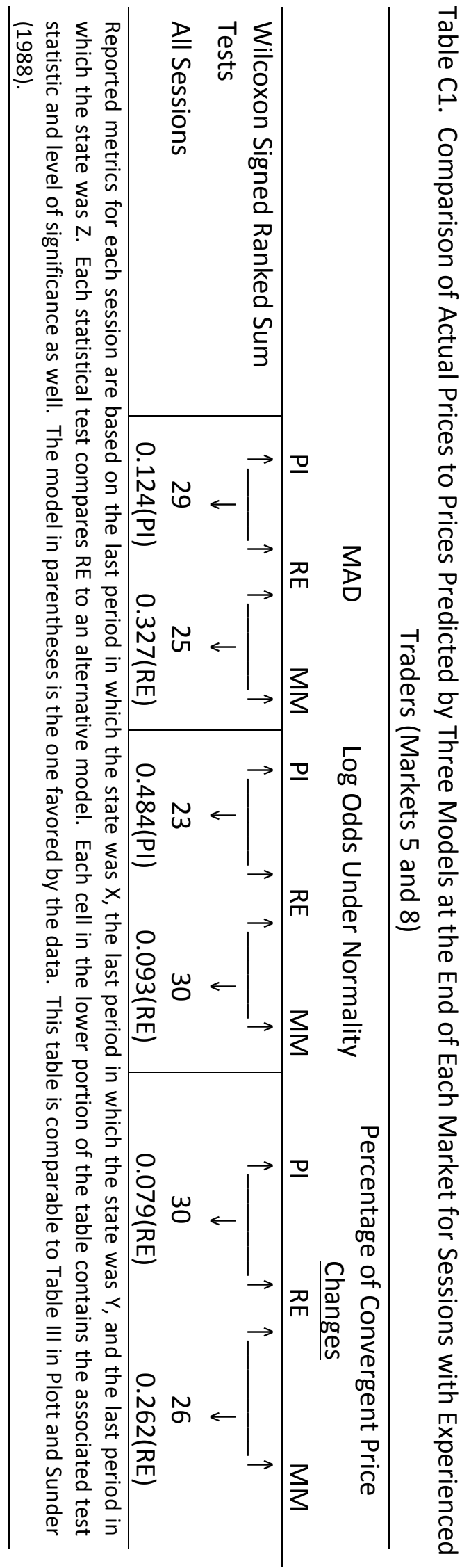

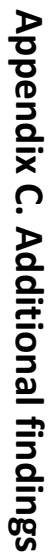




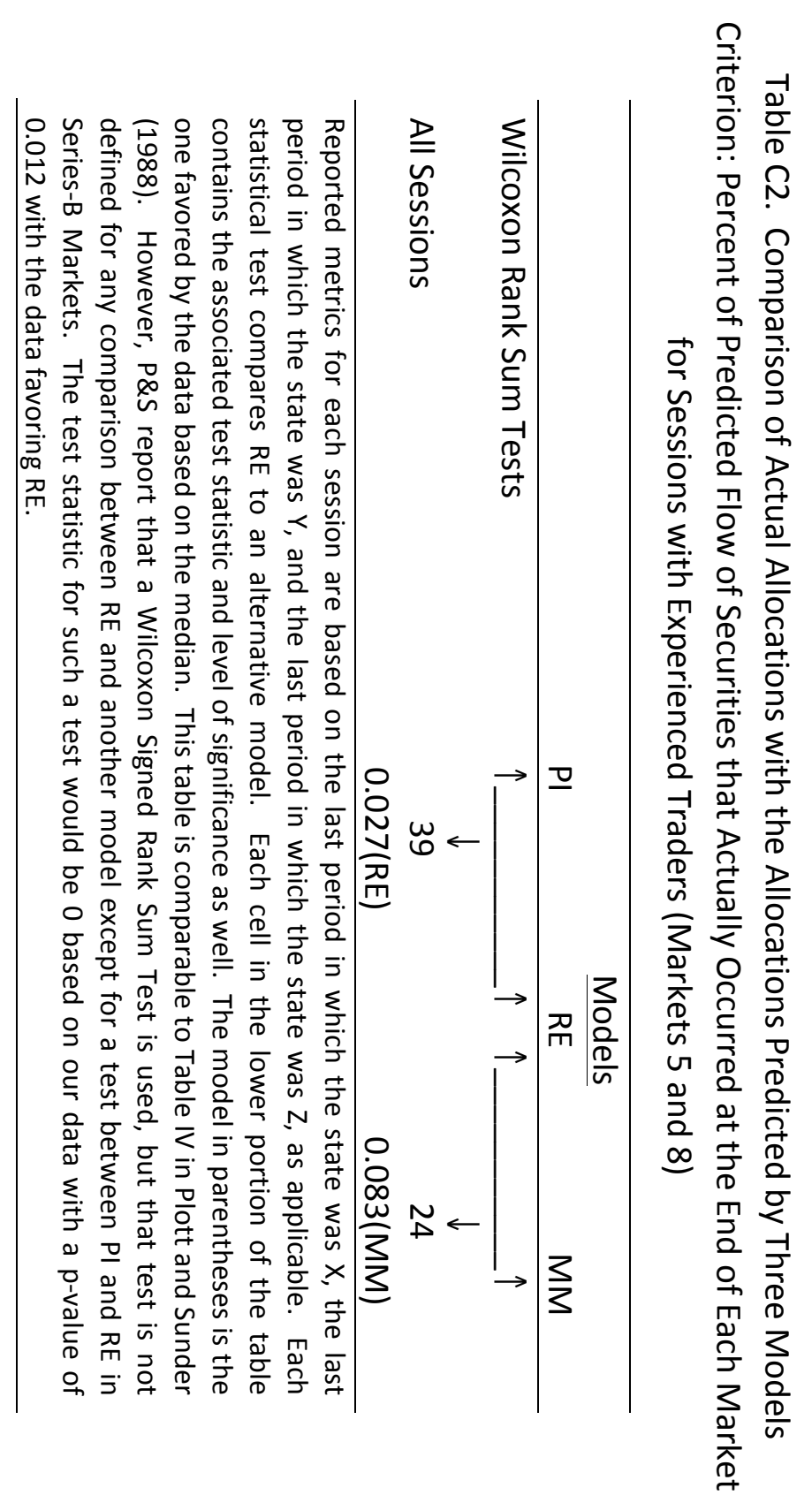




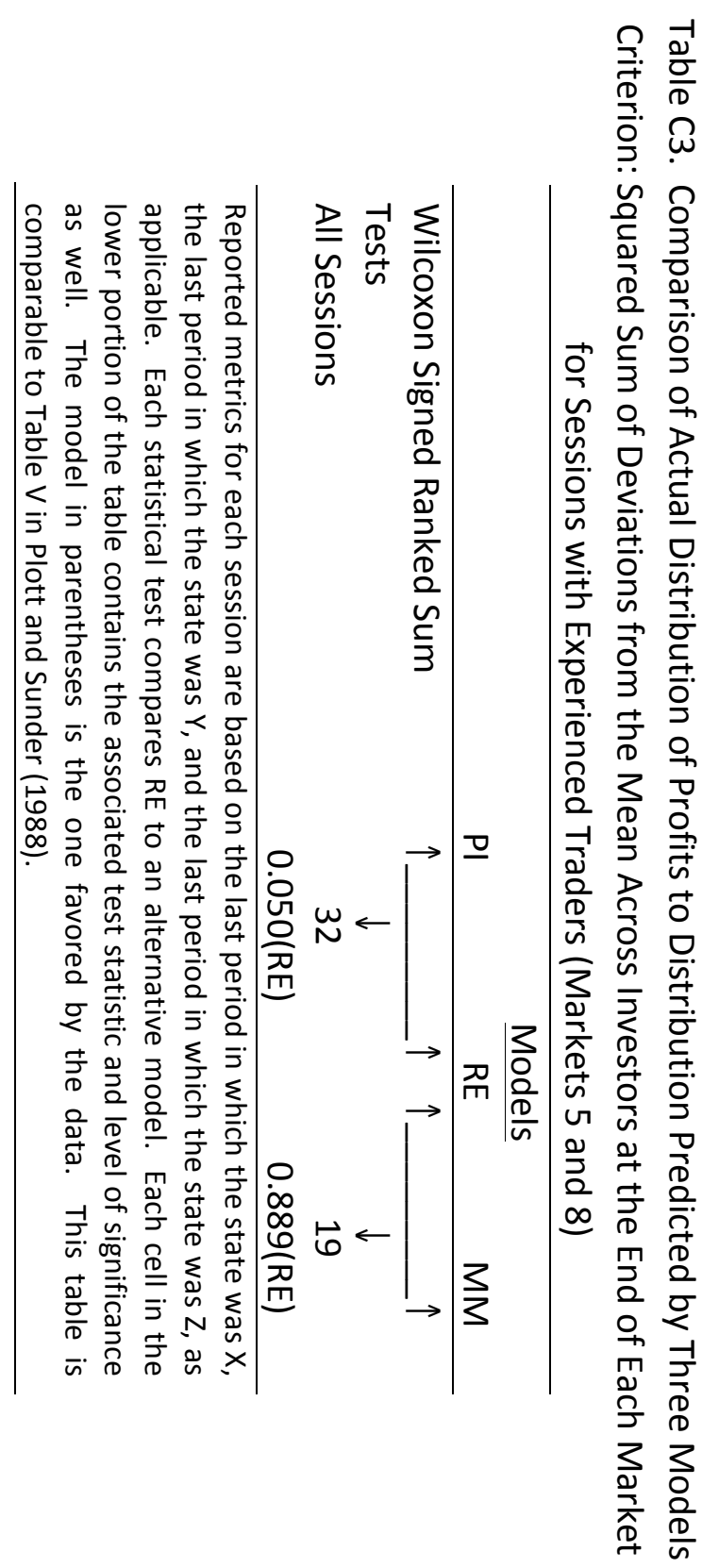

